\title{
Probabilistic observational method for design of surcharges on vertical drains
}

\author{
JOHAN SPROSS* and STEFAN LARSSON†
}

\begin{abstract}
Preloading with a surcharge is today commonly used together with prefabricated vertical drains for embankment construction on clayey soil to accelerate primary consolidation and increase strength. Because of considerable uncertainty related mainly to the rate of consolidation, there is a need to account for this in the vertical drain and surcharge design to ensure quality in the embankment construction. Addressing this issue, the paper presents a novel probabilistic design methodology that is compatible with the observational method. The procedure evaluates the suitable surcharge load to be used in combination with a vertical drain design in order to ensure that the established design criteria are satisfied with acceptable probability.
\end{abstract}

KEYWORDS: consolidation; embankments; ground improvement

\section{INTRODUCTION}

Preloading with a surcharge is today commonly used together with prefabricated vertical drains (PVDs) for embankment construction on clayey soil to accelerate primary consolidation and increase strength. In essence, by installing a pattern of PVDs in a loaded clay stratum consolidation will occur both vertically and horizontally (radially) towards the drains such that the spatially averaged degree of consolidation can be expressed as a function of time, $t$ (Carrillo, 1942)

$$
U(t)=1-\left[1-U_{\mathrm{v}}(t)\right]\left[1-U_{\mathrm{h}}(t)\right]
$$

where the average degree of vertical consolidation is given by Terzaghi's consolidation theory

$$
U_{\mathrm{v}}(t)=1-8 \sum_{i=0}^{\infty} \frac{\exp \left\{-[\pi(2 i-1)]^{2} c_{\mathrm{v}} t /\left(2 h_{\mathrm{dr}}\right)^{2}\right\}}{[\pi(2 i-1)]^{2}}
$$

and the average degree of horizontal consolidation can be expressed as

$$
U_{\mathrm{h}}(t)=1-\exp \left(-\frac{2 c_{\mathrm{h}} t}{r_{\mathrm{e}}^{2} F}\right)
$$

where $c_{\mathrm{v}}$ and $c_{\mathrm{h}}$ are the vertical and horizontal coefficients of consolidation; $h_{\mathrm{dr}}$ is the maximum vertical drain path; $r_{\mathrm{e}}$ is the radius of the influence zone of a PVD; and $F$ describes the effect of drain spacing, soil disturbance and well resistance.

The theoretical aspects of soil improvement with vertical drains have been studied exhaustively. Starting with pioneering work by Porter (1936), Barron (1948) and Kjellman (1948), considerable insight into the effect of vertical drains on the consolidation process has been gained over the years.

Manuscript received 19 February 2019; revised manuscript accepted 4 November 2019. Published online ahead of print 10 December 2019.

Discussion on this paper closes on 1 July 2021, for further details see p. ii.

Published with permission by the ICE under the CC-BY 4.0 license. (http://creativecommons.org/licenses/by/4.0/)

* Division of Soil and Rock Mechanics, KTH Royal Institute of Technology, Stockholm, Sweden (Orcid:0000-0001-5372-7519).

$\uparrow$ Division of Soil and Rock Mechanics, KTH Royal Institute of Technology, Stockholm, Sweden (Orcid:0000-0001-9615-4861).
Hansbo $(1979,1981)$ developed the design procedure, while the smear effect in particular has since been extensively investigated (e.g. Atkinson \& Eldred, 1981; Bergado et al., 1991; Indraratna \& Redana, 1997, 1998; Hird \& Moseley, 2000; Sharma \& Xiao, 2000; Hird \& Sangtian, 2002; Walker \& Indraratna, 2007; Rujikiatkamjorn et al., 2013; Zhou \& Chai, 2017). Many recent studies focus on development of analytical and numerical solutions to various design situations for PVDs (e.g. Lei et al., 2015; Indraratna et al., 2016; Geng \& Yu, 2017; Indraratna et al., 2017; Nguyen \& Kim, 2019). Settlement prediction and verification from measurements have also gained attention lately (Chung et al., 2014; Stark et al., 2017; Abdullah et al., 2018; Guo et al., 2018). A comprehensive benchmarking exercise for settlement prediction (Indraratna et al., 2018a), two studies on vacuum-surcharge preloading (Ni et al., 2019; Wang et al., 2019) and a case study (Wang et al., 2018) were also published recently.

As a consequence of the considerable amount of research on vertical drains, there exist today many alternative analytical models of $F$ (in equation (3)) for geotechnical design of PVDs; see for example Abuel-Naga et al. (2015). From a design perspective, however, the effect of aleatory and epistemic uncertainties also needs to be considered. In fact, Müller \& Larsson (2013) found that uncertainties in the relevant geotechnical parameters - mainly in $c_{\mathrm{h}}$ - will likely affect the design substantially more than the choice of model for $F$. Nonetheless, the effect of uncertainty is much less studied, although Hong \& Shang (1998) and Zhou et al. (1999) studied the effect of uncertainty on drain spacing. Bari et al. (2013, 2016) and Bari \& Shahin (2014) later developed these concepts, also taking into account spatial variation in $c_{\mathrm{h}}$. Huang et al. (2010), Bong et al. (2014) and Bong \& Stuedlein (2018) also investigated consolidation behaviour with spatially variable soil properties, while Müller et al. (2016) analysed probabilistically the effect of PVDs on the increase in undrained shear strength during the staged construction of an embankment.

However, no established reliability-based procedure exists today for design of surcharge loads in combination with PVDs for accelerated consolidation under embankments. Taking on this challenge, this paper presents a novel probabilistic design procedure based on the observational method (Peck, 1969). The procedure is compatible with the general reliability framework for the observational method 
outlined by Spross \& Johansson (2017). Considering that the presented design procedure agrees with the definition of the observational method (CEN, 2004), this paper also addresses the request for studies on applications and proper use of the observational method that was expressed at the Institution of Civil Engineers (ICE) symposium held in 1995 on the Géotechnique special issue on the observational method (Nicholson, 1996).

\section{THE OBSERVATIONAL METHOD}

Introduced by Peck (1969), the observational method offers an alternative to conventional design. The method is often put forward for its potential for savings when it is difficult to predict geotechnical behaviour. Although the term 'observational method' is sometimes used to refer to all kinds of design based on observations, it is used here in strict accordance with section 2.7 in Eurocode 7 (CEN, 2004), cited in full in Table 1. Studies discussing applications of the observational method include Wu (2011), Prästings et al. (2014), Spross \& Larsson (2014), Spross et al. (2016), Spross \& Johansson (2017), Bjureland et al. (2017), Fuentes et al. (2018) and Spross \& Gasch (2019).

\section{OVERVIEW OF DESIGN PROCEDURE \\ Limit state}

When loading soft clay, significant settlement can be expected. From a serviceability point of view, the relevant limit state to analyse for an embankment concerns the occurrence of residual settlements after completion of the embankment and the superstructure

$$
G=\Delta s_{\text {allow }}-\Delta S
$$

where $\Delta s_{\text {allow }}$ is the allowable residual settlement and $\Delta S$ is the occurring residual settlement. The conceptual idea of the proposed design procedure is to ensure that this serviceability limit state is only violated with an acceptable target failure probability - that is, $P(G<0)=p_{\mathrm{FT}}$.

Considering that compression of clay consists of primary compression (consolidation) and secondary compression (mainly creep), the design concept needs to manage both aspects. However, secondary compression can be limited by ensuring that the preloading causes sufficient overconsolidation (Jamiolkowski \& Lancellotta, 1981; Alonso et al., 2000; Han, 2015; Indraratna et al., 2018b), which is useful in the practical design situation. This permits the considerable simplification of taking only primary consolidation settlement into account in the design analysis, as is done in this paper. To ensure only limited compression after completion, sufficient primary compression settlement, $s_{\text {target}}$, thus needs to develop during the preloading. Making $s_{\text {target }}$ a prescribed settlement target to be met during the preloading phase to satisfy $P(G<0)=p_{\text {FT }}$, equation (4) can be reformulated into

$$
G=s_{\text {target }}+\Delta s_{\text {allow }}-S_{\infty}
$$

where $S_{\infty}$ is the predicted long-term primary compression settlement caused by the embankment load. The establishment of the $s_{\text {target }}$ value is conceptually visualised in Fig. 1. In the authors' opinion, $\Delta s_{\text {allow }}$ can in practice be set to 0 to reserve a margin for any occurrence of secondary compression after completion or any creep possibly occurring during primary consolidation (Leroueil, 1996; Hawlader et al., 2003; Feng \& Yin, 2018). This implies that the $s_{\text {target }}$ value can be determined as the percentile of the distribution of $S_{\infty}$ that corresponds to the predetermined $p_{\mathrm{FT}}$.

The limit state $G$ is a function of the random variables affecting primary consolidation settlements, which are collected in a vector $\boldsymbol{X}=\left[X_{1}, X_{i}, \ldots, X_{m}\right]$. In this paper, these correspond to the vertical and horizontal coefficients of consolidation, the unit weight and natural water content of the clay, the unit weight of the embankment material and four settlement parameters evaluated from constant-rateof-strain (CRS) oedometer tests, as detailed in the illustrative design example.

\section{Design criteria and execution}

By preloading with a surcharge that is placed on top of the embankment for some time, the consolidation process can be sped up, allowing $s_{\text {target }}$ to be reached before a predefined maximum allowable preloading time, $t_{\max }$. When $s_{\text {target }}$ is reached, the surcharge is unloaded and the superstructure completed, after which the embankment is taken into service. Designing the embankment with the observational method, the designing engineer's task is to select a PVD design (e.g. drain type and spacing) and a surcharge load that in

Table 1. Principles of the observational method cited from section 2.7 in Eurocode 7 (CEN, 2004)

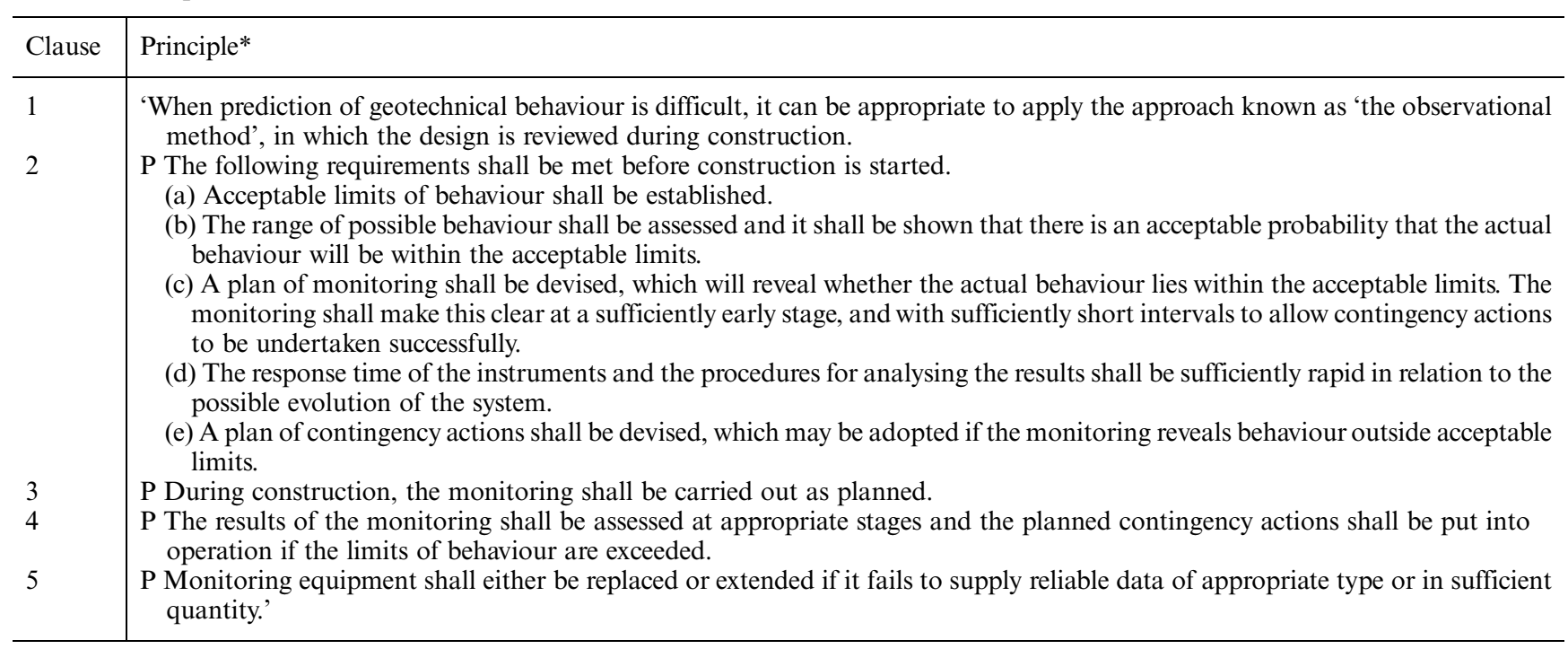

*'P' indicates a principle, which must not be violated. 


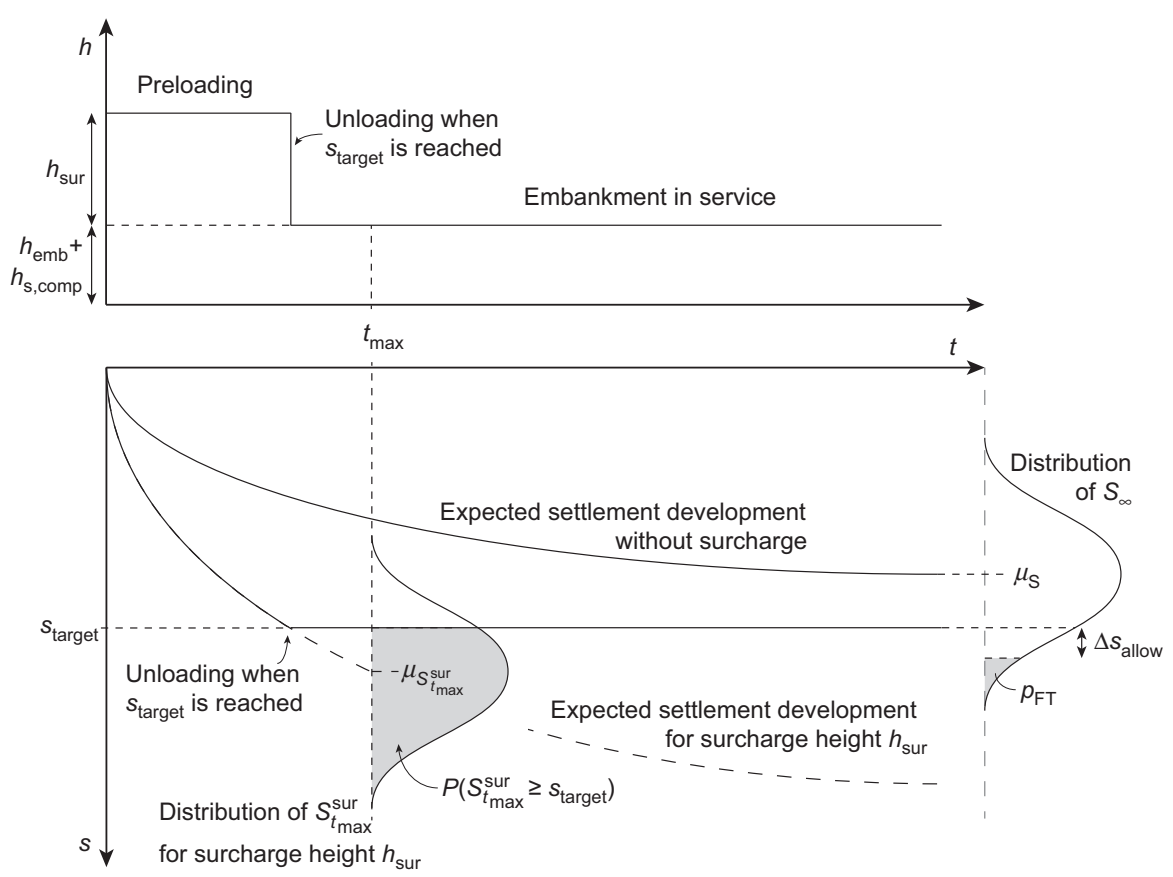

Fig. 1. Conceptual idea of the design procedure. Top: embankment height plotted against time. Bottom: developed settlement plotted against time. The $S_{\infty}$ is used to determine the $s_{\text {target }}$ value. To ensure that $\Delta S_{\text {allow }}$ is only exceeded with $p_{\mathrm{FT}}$, a surcharge height $h_{\text {sur }}$ is selected so that the $s_{\text {target }}$ value and $\mathrm{OCR}=1 \cdot 10$ are attained within $t_{\max }$ with acceptable probability

combination satisfy two criteria: $(a)$ that the predicted but uncertain settlement $S_{t_{\max }}^{\text {sur }}$ that is caused by the preloading until $t=t_{\max }$ will reach $s_{\text {target }}$ with acceptable probability, $p_{\text {acc }}$

$$
P\left(S_{t_{\max }}^{\text {sur }} \geq s_{\text {target }}\right) \geq p_{\text {acc }}
$$

and $(b)$ that the overconsolidation ratio, OCR, after unloading the surcharge at $t_{\max }$ will exceed OCR $_{\text {target }}=1 \cdot 10$ with acceptable probability in the middle of the clay stratum

$$
P\left(\mathrm{OCR}_{t_{\max }}^{\text {sur }} \geq 1 \cdot 10\right) \geq p_{\text {acc }}
$$

The first criterion ensures that a sufficiently large surcharge load is applied initially, to allow the probabilistically determined $s_{\text {target }}$ value to be reached with the probability $p_{\text {acc }}$ within the available timeframe $\left(t<t_{\text {max }}\right)$. Fig. 1 illustrates the probability $P\left(S_{t_{\max }}^{\text {sur }} \geq s_{\text {target }}\right)$ for some selected initial surcharge heights, $h_{\text {sur. }}$ Since the observational method allows changes ('contingency actions') to the preliminary design during construction - that is increase of the surcharge height during the preloading - the main embankment design requirement $P(G<0)=p_{\mathrm{FT}}$ can in principle be satisfied regardless of applied initial surcharge height. This implies that the $p_{\text {acc }}$ will depend on the risk appetite of the decision maker in the project at hand, who will face the cost of contingency actions or project delay with the probability $1-p_{\text {acc }}$ at most (see details in the later section entitled 'Discussion').

The second criterion ensures that significant secondary compression is avoided. The requirement for $\mathrm{OCR}_{t_{\max }}^{\mathrm{sur}} \geq$ $1 \cdot 10$ follows the general technical requirements and guidance for geotechnical works issued by the Swedish Transport Administration (STA, 2013a, 2013b). Other target values than $\mathrm{OCR}_{t_{\max }}^{\text {sur }} \geq 1.10$ can be applied in a straightforward way based on local regulations. 'Acceptable probability' in this context refers to requirement 2 (b) in the observational method (Table 1); because of the significant uncertainties of the geotechnical conditions in the ground, the surcharge height can only be selected based on the probability that the corresponding load will be sufficient to meet the two design criteria (equations (6) and (7)).
During the preloading, monitoring of settlements (requirement 2c) and use of contingency actions (requirement 2e) ensure that the two criteria are actually met, so that the serviceability limit state (equation (5)) is violated - that is, post-completion primary compression occurs - only with the probability $p_{\mathrm{FT}}$ at most. A suitable contingency action if the monitoring indicates too slow a rate of settlement may be to increase the surcharge load; if the rate is faster than required, unloading the surcharge is required when both criteria are satisfied (for details see the Illustrative design example). An overview of the conceptual idea is provided in Fig. 1 and a flowchart of the procedure in Fig. 2.

\section{PROBABILISTIC SOIL CHARACTERISATION \\ Principles for modelling of the uncertainty}

To be able to assess the design criteria (equations (6) and (7)), the random variables in $\boldsymbol{X}$ need to be evaluated. In this paper, a Bayesian approach to statistics is taken, since this is the most reasonable approach to interpret structural failure probabilities. This implies that probabilities are interpreted as a degree of belief in an event (rather than as the observable relative frequency of the event after many repeated trials, which the classical frequentist approach requires). With a Bayesian approach, the calculated failure probabilities will be correct on average for a large number of structures; Vrouwenvelder (2002), Baecher \& Christian (2003) and other textbooks on structural reliability analysis provide more detailed discussions on this matter.

As consolidation settlement is an averaging process, the mean value of each geotechnical parameter in $\boldsymbol{X}=\left[X_{1}, X_{i}\right.$, $\left.\ldots, X_{m}\right]$ is modelled as a random variable (where subscript $i$ henceforth in this chapter is dropped for convenience)

$$
\bar{X}=\bar{X}_{\mathrm{m}} T=\bar{x}_{\mathrm{m}} \varepsilon T
$$

where $\bar{X}_{\mathrm{m}}$ is the uncertain mean value of the measured geotechnical property with expected value $\bar{x}_{\mathrm{m}} ; \varepsilon$ is an error factor that describes the inherent variability and any statistical uncertainty and measurement errors in the 


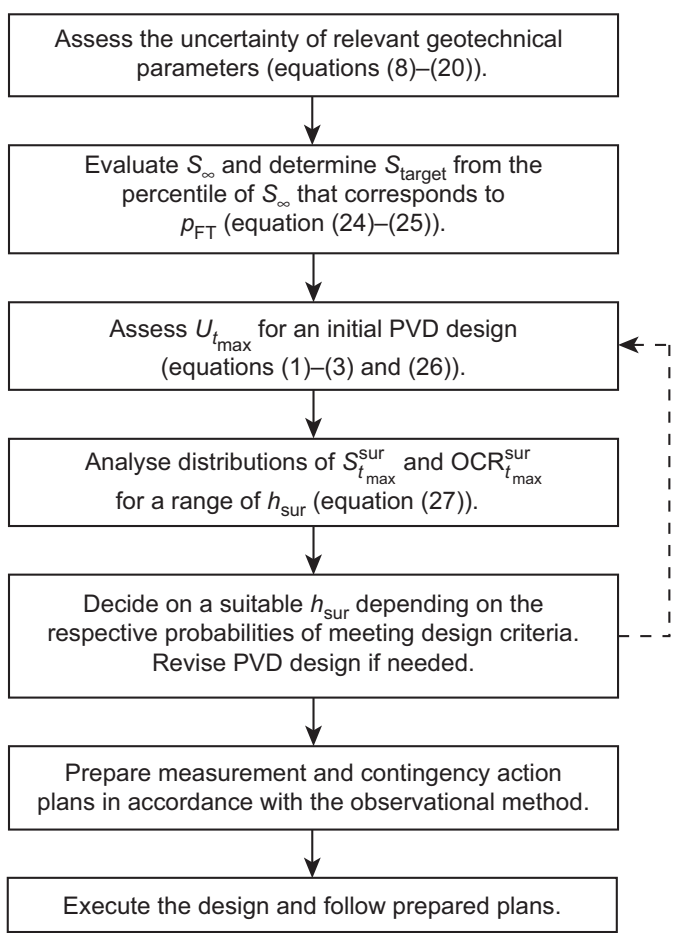

Fig. 2. Flowchart for probabilistic design of surcharges on vertical drains in accordance with the observational method

evaluation of $\bar{X}_{\mathrm{m}}$; and $T$ represents a transformation model (in case of indirect measurements) that also may contain a random error, which accounts for any uncertainty in the transformation model between the measured property and the sought geotechnical parameter. In this paper, the respective $\varepsilon$ of the investigated geotechnical parameters is assumed to be log-normally distributed, as is common practice (e.g. Lacasse \& Nadim, 1996; Baecher \& Christian, 2003; Fenton \& Griffiths, 2008; Huang et al., 2010), while transformation errors are assumed either normally or log-normally distributed. Transformation models $T$ are therefore treated separately (see equation (20)). Similar statistical models have been described and used by, for example, Phoon \& Kulhawy (1999), Ching \& Phoon (2012), Bergman et al. (2013) and Müller et al. (2014, 2016).

To evaluate the uncertainty of the mean value of each measured geotechnical property, $\bar{X}_{\mathrm{m}}=\bar{x}_{\mathrm{m}} \varepsilon$, based on the available geotechnical investigations, all data can be transformed with the natural logarithm to allow working with normal distributions. The $\bar{X}_{\mathrm{m}}$ can thus be rewritten to

$$
\ln \bar{X}_{\mathrm{m}}=\ln \left(\bar{x}_{\mathrm{m}} \varepsilon\right)=\ln \bar{x}_{\mathrm{m}}+\varepsilon^{\{\ln \}}
$$

where $\ln \bar{x}_{\mathrm{m}}$ denotes the expected value based on $n$ data points that have been transformed with the natural logarithm and $\varepsilon^{\{\ln \}}$ is the associated zero-mean normally distributed error.

If there is no trend with depth, $z$, the evaluation of $\ln \bar{x}_{\mathrm{m}}$ is straightforward, but when a trend exists, which may be for geological reasons, the trend can be considered by evaluating the variability around a regression line. Several models are possible, but in this paper a simple normal regression is used with variance estimated from the $n$ available data points that have already been transformed with the natural logarithm, such that

$$
\ln \bar{x}_{\mathrm{m}}=\hat{a}+\hat{b} z
$$

where $\hat{a}$ and $\hat{b}$ are regression parameters evaluated from the log-transformed data points.
The error $\varepsilon$ can be divided into three multiplied lognormally distributed error components

$$
\varepsilon=\varepsilon_{\mathrm{inh}} \varepsilon_{\mathrm{st}} \varepsilon_{\mathrm{me}}
$$

where $\varepsilon_{\text {inh }}$ represents the inherent variability of the measured property after averaging it over the failure domain; $\varepsilon_{\mathrm{st}}$ represents the statistical uncertainty in the estimation of the mean value; and $\varepsilon_{\text {me }}$ represents the measurement error related to the estimation of the mean value. Each $\log$ normally distributed component has a zero mean of the corresponding normal distribution and corresponding variances $\sigma_{\mathrm{inh}}^{\{\ln \} 2}, \sigma_{\mathrm{st}}^{\{\ln \} 2}$ and $\sigma_{\mathrm{me}}^{\{\ln \} 2}$ as parameters. With this model, the $\bar{X}_{\mathrm{m}}$ can be characterised by the log-normal distribution $L N\left(\ln \bar{x}_{\mathrm{m}}, \sigma_{\varepsilon}^{\{\ln \} 2}\right), \quad$ where $\quad \sigma_{\varepsilon}^{\{\ln \} 2}=\sigma_{\operatorname{inh}}^{\{\ln \} 2}+$ $\sigma_{\text {st }}^{\{\ln \} 2}+\sigma_{\text {me }}^{\{\ln \} 2}$, after having applied the rule for multiplication of log-normally distributed variables. The variance of each error component is derived in the following subsections.

\section{Assessment of inherent variability}

The variability of the measured data points may include both an inherent variability and a measurement error - that is, $\varepsilon_{\text {data }}^{\{\ln \}}=\varepsilon_{\text {inh }}^{\{\ln \}} \varepsilon_{\mathrm{me}, \mathrm{m}}^{\{\ln \}}$, where $\varepsilon_{\mathrm{me}, \mathrm{m}}^{\{\ln \}}$ is the measurement error related to each log-transformed measured data point. Applying the rule for multiplied log-normally distributed variables and rearranging the terms, the variance of the natural logarithm of the inherent variability is

$$
\sigma_{\mathrm{inh}}^{\{\ln \} 2}=\sigma_{\mathrm{data}}^{\{\ln \} 2}-\sigma_{\mathrm{me}, \mathrm{m}}^{\{\ln \{2}
$$

where $\sigma_{\mathrm{me}, \mathrm{m}}^{\{\ln \} 2}=\ln \left[\operatorname{COV}\left(\varepsilon_{\mathrm{me}, \mathrm{m}}\right)^{2}+1\right]$ in which the error $\varepsilon_{\mathrm{me}, \mathrm{m}}$ is the reported error of the applied measurement method (see e.g. the compilation by Phoon \& Kulhawy (1999) and Müller et al. (2016)).

In principle, however, the effect of $\varepsilon_{\mathrm{inh}}^{\{\ln \}}$ on $\ln \bar{X}_{\mathrm{m}}$ is partially affected by the scale of the structural failure, which requires the evaluation of the variance function $\Gamma^{2}$ to assess the variance reduction. However, in this paper it is for simplicity assumed that the clay layer is sufficiently thick to make the settlement a fully averaging process; consequently, $\Gamma^{2}=0$, which eradicates the effect of local zones in the clay that deviate from the mean value. If there is a less thick clay layer, the reader is referred to, for example, Fenton \& Griffiths (2008) or Vanmarcke (2010) for details on the evaluation of $\Gamma^{2}$.

\section{Evaluation of statistical uncertainty}

With a linear trend line with depth, the uncertainty of $\varepsilon_{\mathrm{st}}^{\{\ln \}}$ at a certain depth $z$ is calculated from the general normal regression process with unknown variance (Raiffa \& Schlaifer, 1961; Tang, 1980; Ang \& Tang, 2007)

$$
\sigma_{\mathrm{st}}^{\{\ln \} 2}=\left[\boldsymbol{z}\left(\mathbf{Z}^{\mathrm{T}} \mathbf{Z}\right)^{-1} \boldsymbol{z}^{\prime}+\mathbf{I}\right] \sigma_{\mathrm{inh}}^{\{\ln \} 2} \frac{v}{v-2}
$$

where $\boldsymbol{z}=\left[\begin{array}{lllll}1 & z & z^{2} & \cdots & z^{r}\end{array}\right]$; I is the identity matrix; $v$ denotes the number of degrees of freedom, which in this case is equal to $n-1$, and

$$
\mathbf{Z}=\left[\begin{array}{cccc}
1 & z_{1} & \cdots & z_{1}^{r} \\
1 & z_{2} & \cdots & z_{2}^{r} \\
\vdots & \vdots & \ddots & \vdots \\
1 & z_{n} & \cdots & z_{n}^{r}
\end{array}\right]
$$

where the rows represent the $n$ depths at which independent measurements were taken. Assuming a linear trend, $r=1$, 
which according to Tang (1980) simplifies equation (13) into

$$
\sigma_{\mathrm{st}, z}^{\{\ln \} 2}=\psi_{z} \sigma_{\mathrm{inh}}^{\{\ln \} 2}
$$

where the factor $\psi_{z}$ is a function of $z$ (henceforth in this section denoted by subscript $z$ )

$$
\psi_{z}=\frac{n-1}{n-3}\left\{\frac{1}{n}\left[1+\frac{n}{n-1} \frac{(z-\bar{z})^{2}}{\sigma_{z}^{2}}\right]\right\}
$$

in which $\bar{z}$ is the sample mean of the depths where the measurements were taken and $\sigma_{z}^{2}$ is the sample variance of the respective depths $z_{i}$. (If no linear trend exists, $\psi=1 / n$, which gives the straightforward result $\sigma_{\mathrm{st}}^{\{\ln \} 2}=\sigma_{\mathrm{inh}}^{\{\ln \}^{2}} / n$.)

\section{Evaluation of measurement error}

Lastly, the uncertainty of $\varepsilon_{\mathrm{me}}^{\{\ln \}}$ (see equation (12)), in the evaluation of the uncertainty related to the mean value $\ln \bar{X}_{\mathrm{m}}$, decreases with the number of independent measurements of the property

$$
\sigma_{\mathrm{me}}^{\{\ln \} 2}=\frac{\sigma_{\mathrm{me}, \mathrm{m}}^{\{\ln \} 2}}{n}
$$

\section{Evaluation of the total uncertainty of the parameter}

Combining equations (12)-(17) and assuming a fully averaging process such that $\sigma_{\text {inh }}^{\{\ln \} 2} \Gamma^{2}=0$, the total variance of $\varepsilon^{\{\ln \}}$ becomes a function of $z$ and evaluates to

$$
\begin{aligned}
& \sigma_{\varepsilon, z}^{\{\ln \} 2}=\sigma_{\mathrm{st}, z}^{\{\ln 2}+\sigma_{\mathrm{me}}^{\{\ln \} 2} \\
& =\frac{n-1}{n-3}\left\{\frac{1}{n}\left[1+\frac{n}{n-1} \frac{(z-\bar{z})^{2}}{\sigma_{z}^{2}}\right]\right\} \sigma_{\mathrm{inh}}^{\{\ln \} 2}+\frac{\sigma_{\mathrm{me}, \mathrm{m}}^{\{\ln 2}}{n}
\end{aligned}
$$

The mean value and the variance of $\bar{X}_{\mathrm{m}}$ as functions of $z$ (equations (9), (10) and (18)) can be found by transforming the parameters of the lognormal distribution through

$$
\begin{aligned}
& \mu_{\bar{X} \mathrm{~m}, z}=\exp \left[\ln \bar{x}_{\mathrm{m}, z}+\frac{\sigma_{\varepsilon, z}^{\{\ln \} 2}}{2}\right] \\
& \sigma_{\bar{X} \mathrm{~m}, z}^{2}=\left[\exp \left(\sigma_{\varepsilon, z}^{\{\ln \} 2}\right)-1\right] \times \exp \left(2 \ln \bar{x}_{\mathrm{m}, z}+\sigma_{\varepsilon, z}^{\{\ln \} 2}\right)
\end{aligned}
$$

At this point, the effect of transformation uncertainty related to the normally distributed $T$ (in equation (8)) with parameters $\mu_{T}$ and $\sigma_{T}^{2}$ can be taken into account if needed. Assuming no correlation between the transformation uncertainty and the other error components

$$
\begin{aligned}
& \mu_{\bar{X}, z}=\mu_{\bar{X} \mathrm{~m}, z} \mu_{T} \\
& \sigma_{\bar{X}, z}^{2}=\mu_{T}^{2} \sigma_{\bar{X} \mathrm{~m}, z}^{2}+\mu_{\bar{X} \mathrm{~m}, z}^{2} \sigma_{T}^{2}+\sigma_{\bar{X} \mathrm{~m}, z}^{2} \sigma_{T}^{2}
\end{aligned}
$$

As equation (20) combines log-normally and normally distributed variables, numerical simulation of the corresponding probability distribution of $\bar{X}$ is favourable, as discussed in the illustrative example.

\section{SURCHARGE LOAD DESIGN}

\section{Primary consolidation settlement after infinite time}

To determine $s_{\text {target }}$ as the percentile corresponding to the probability $P(G<0)=p_{\mathrm{FT}}$ (equation (5)), the distribution of $S_{\infty}$ needs to be evaluated (Fig. 1). In general terms

$$
S_{\infty}=\int_{0}^{h_{\text {clay }}} \frac{\Delta e(z)}{1+e_{0}(z)} \mathrm{d} z
$$

where $\Delta e(z)$ is the change in void ratio at depth $z$ because of the change in effective stress $\Delta \sigma^{\prime}(z)$ at depth $z ; e_{0}(z)$ is the initial void ratio at depth $z$; and $h_{\text {clay }}$ is the total thickness of the saturated clay layer. For most clays, $\Delta e$ can be described by the compression index, $C_{\mathrm{c}}$, evaluated as the slope of the $e-\log \left(\sigma^{\prime}\right)$ plot, such that

$$
\Delta e=C_{\mathrm{c}} \log \left(\frac{\sigma_{0}^{\prime}+\Delta \sigma^{\prime}}{\sigma_{0}^{\prime}}\right)
$$

where $\sigma_{0}^{\prime}$ is the initial vertical stress. However, for soft clays, the assumption that this slope is a straight line is not valid; its application would greatly overestimate the settlement (Larsson, 1986). This paper therefore applies the more detailed approach for the evaluation of the distribution of $S_{\infty}$ that is the standard practice for the soft Swedish clays. (The presented design procedure can, however, be used in a straightforward way also with the $C_{\mathrm{c}}$.) The approach is based on CRS oedometer tests and allows straightforward prediction of primary consolidation settlements for practical engineering purposes from the shape of stress-strain curves (Larsson \& Sällfors, 1986; SIS, 1991). Reformulating equation (21)

$$
S_{\infty}=\int_{0}^{h_{\text {clay }}} \Delta \epsilon(z) \mathrm{d} z
$$

where $\Delta \epsilon(z)$ is the change in strain at depth $z$ because of $\Delta \sigma^{\prime}(z)$. The shape of the stress-strain curves is described with the parameters preconsolidation pressure $\sigma_{\mathrm{c}}^{\prime}$, limit pressure $\sigma_{\mathrm{L}}^{\prime}$ towards increasing soil modulus, two soil moduli $M_{0}$ and $M_{\mathrm{L}}$, a modulus number $M^{\prime}=\Delta M / \Delta \sigma^{\prime}$ for the part where the modulus increases linearly with the effective stress, and a baseline intersection parameter $a$ (Fig. 3). In essence, the method implies that the stress-strain curve is divided into three parts with different inclination (soil moduli). To find the $\Delta \epsilon(z)$ corresponding to some $\Delta \sigma^{\prime}(z)$, one can in principle enter the range of $\Delta \sigma^{\prime}(z)$ - that is $\left[\sigma_{0}^{\prime}(z), \sigma_{0}^{\prime}(z)+\Delta \sigma^{\prime}(z)\right]-$ on the horizontal axis in Fig. 3 and read the corresponding strain range off the vertical axis. This procedure can be mathematically described by the following set of equations, which are used depending on what part of the curve the range of $\Delta \sigma^{\prime}(z)$ covers (Larsson \& Sällfors, 1986)

$$
\begin{aligned}
& \Delta \epsilon=\frac{\Delta \sigma^{\prime}}{M_{0}} \text { when } \sigma_{0}^{\prime}+\Delta \sigma^{\prime} \leq \sigma_{\mathrm{c}}^{\prime} \\
& \Delta \epsilon=\frac{\sigma_{\mathrm{c}}^{\prime}-\sigma_{0}^{\prime}}{M_{0}}+\frac{\sigma_{0}^{\prime}+\Delta \sigma^{\prime}-\sigma_{\mathrm{c}}^{\prime}}{M_{\mathrm{L}}} \text { when } \sigma_{\mathrm{c}}^{\prime}<\sigma_{0}^{\prime}+\Delta \sigma^{\prime} \leq \sigma_{\mathrm{L}}^{\prime} \\
& \Delta \epsilon=\frac{\sigma_{\mathrm{c}}^{\prime}-\sigma_{0}^{\prime}}{M_{0}}+\frac{\sigma_{\mathrm{L}}^{\prime}-\sigma_{\mathrm{c}}^{\prime}}{M_{\mathrm{L}}}+\frac{1}{M^{\prime}} \ln \frac{\sigma_{0}^{\prime}+\Delta \sigma^{\prime}-a}{\sigma_{\mathrm{L}}^{\prime}-a} \\
& \text { when } \sigma_{\mathrm{L}}^{\prime}<\sigma_{0}^{\prime}+\Delta \sigma^{\prime}
\end{aligned}
$$

where $a=\sigma_{\mathrm{L}}^{\prime}-M_{\mathrm{L}} / M^{\prime}$. Evaluation details regarding the settlement parameters from CRS tests are presented in the Appendix.

To simplify, the clay stratum can be divided into $l$ separate layers, where each layer is thick enough to allow the assumption of negligible spatial correlation (made in equation (18)). This gives

$$
S_{\infty} \approx \sum_{j=1}^{l} h_{j} \Delta \epsilon_{j}
$$

where $h_{j}$ is the thickness of each layer. All parameters required for the calculation of $\Delta \epsilon_{j}$ are evaluated for the centre of the respective layer based on the CRS oedometer tests and the corresponding uncertainty is taken into account using equations (8)-(20). Having evaluated equation (20) for all relevant geotechnical parameters, a probability distribution of $S_{\infty}$ (equations (24) and (25)) is simulated to obtain a first guess of $s_{\text {target }}$ from equation (5). Since the embankment 


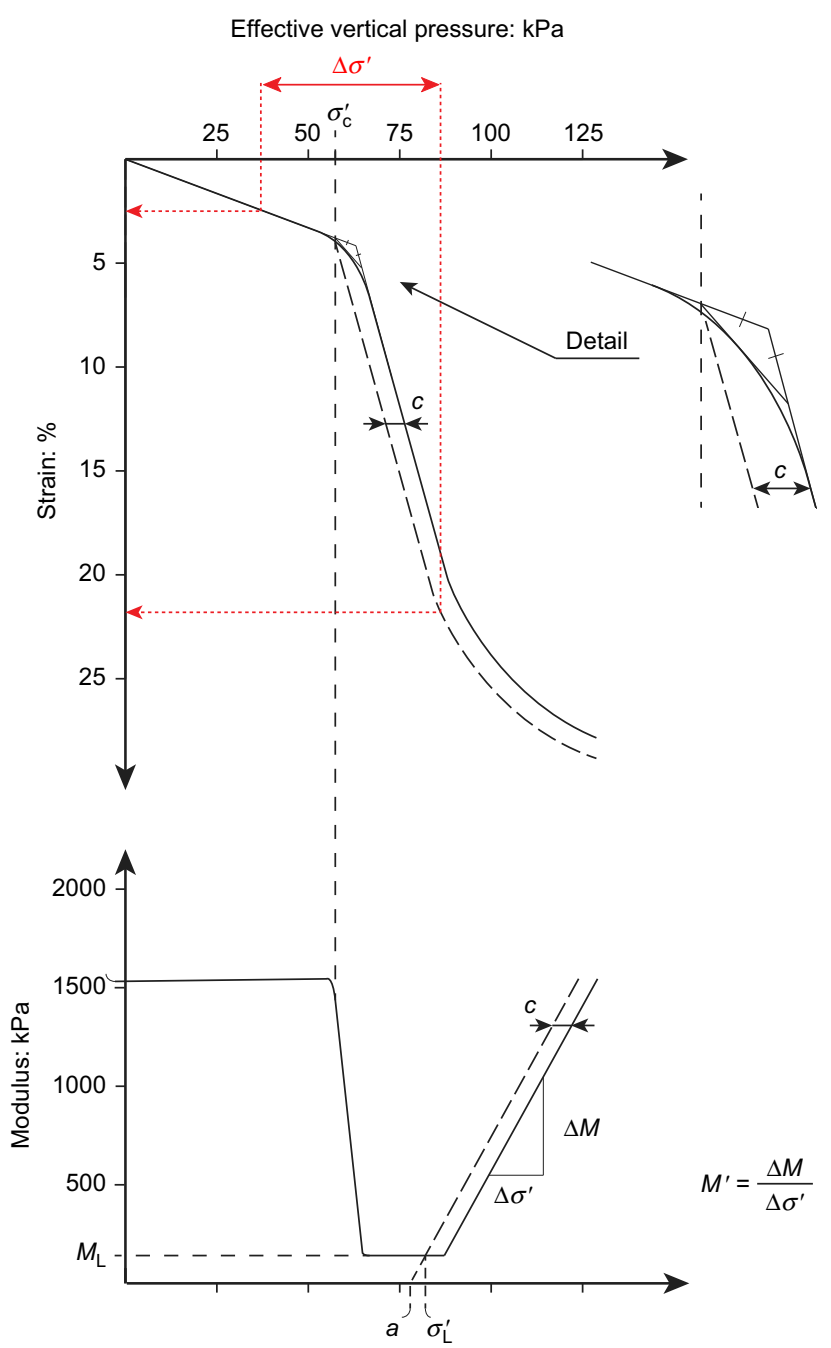

Fig. 3. Definition of settlement parameters based on CRS tests (Larsson \& Sällfors, 1986). The strain corresponding to an applied load can be read off the vertical axis, as shown with dotted lines. The settlement parameters describe this relationship mathematically. Details of their evaluation are summarised in the Appendix

height needs to be compensated with a height $h_{\mathrm{s}, \mathrm{comp}}=s_{\text {target }}$ for the occurring consolidation, $\Delta \sigma^{\prime}$ needs to be iteratively adjusted with respect to both the obtained $s_{\text {target }}$ and the volume of dry crust and embankment material submerged under the groundwater level. Fig. 4 shows this principle: to end up at the intended embankment height $h_{\mathrm{emb}}$ above the ground level after unloading of the surcharge, the initial total embankment height at the beginning of the preloading needs

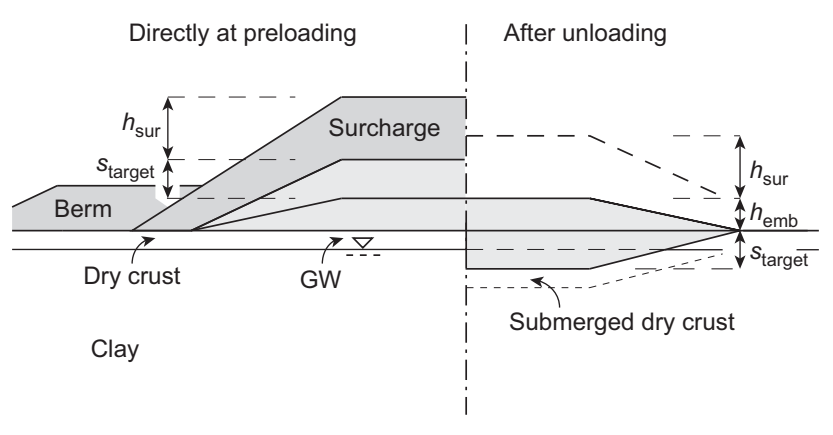

Fig. 4. Schematic illustration of embankment preloading and the situation after unloading. To end up with an embankment height of $h_{\text {emb }}$ after unloading the surcharge, the initial embankment height needs to be compensated with a height $\boldsymbol{h}_{\mathrm{s}, \mathrm{comp}}=s_{\text {target}}$, because of the occurring settlement (GW, groundwater level)

$$
F=\ln \left(\frac{r_{\mathrm{e}}}{r_{\mathrm{w}}}\right)-\frac{3}{4}+\left(\frac{k_{\mathrm{h}}}{k_{\mathrm{h}}^{\prime}}-1\right) \ln \frac{r_{\mathrm{s}}}{r_{\mathrm{w}}}
$$

where $r_{\mathrm{w}}$ is the equivalent drain radius; $k_{\mathrm{h}}$ is the horizontal hydraulic conductivity of the undisturbed soil; $k_{\mathrm{h}}^{\prime}$ is the horizontal hydraulic conductivity of the disturbed soil; and $r_{\mathrm{s}}$ is the radius of the remoulded or disturbed soil (the smear zone). Considering Müller \& Larsson's (2013) findings that, in practice, uncertainties as regards the relevant geotechnical parameters - mainly in $c_{\mathrm{h}}$ - will affect the design more than the choice of model for $F$, the authors find the simplification of disregarding the well resistance reasonable for practical applications.

\section{Selection of surcharge load}

To ensure that the design criteria (equations (6) and (7)) are satisfied with acceptable probability, a sufficiently large surcharge load needs to be selected (Fig. 1). The higher the surcharge, the higher the probability that sufficient settlement (equation (6)) and overconsolidation (equation (7)) will develop during the preloading. To analyse the effect of the surcharge load on this probability, a set of probability distributions of the predicted settlement and OCR after $t_{\max }$ are simulated by computing the following equations for different surcharge loads (i.e. surcharge heights $h_{\text {sur }}$ )

$$
S_{t_{\max }}^{\text {sur }}=S_{\infty}^{\text {sur }} U_{t_{\max }}
$$

where $S_{\infty}^{\text {sur }}$ is the predicted settlement after infinite time for some selected $h_{\text {sur }}$ evaluated with the same principle as shown in equations (24) and (25); $U_{t_{\max }}$ is the degree of consolidation after $t_{\max }$ (equations (1)-(3)); $\gamma_{\mathrm{emb}}$ is the unit weight of the

$$
\mathrm{OCR}_{t_{\max }}^{\text {sur }}=\frac{\sigma_{0}^{\prime}+U_{t_{\max }}\left[\gamma_{\mathrm{emb}}\left(h_{\mathrm{emb}}+h_{\text {sur }}+h_{\text {crust }}\right)+\gamma_{\mathrm{emb}}^{\prime}\left(s_{\text {target }}-h_{\text {crust }}\right)-\gamma_{\mathrm{w}} h_{\text {crust }}\right]}{\sigma_{0}^{\prime}+U_{t_{\max }}\left[\gamma_{\mathrm{emb}}\left(h_{\mathrm{emb}}+h_{\text {crust }}\right)+\gamma_{\mathrm{emb}}^{\prime}\left(s_{\text {target }}-h_{\text {crust }}\right)-\gamma_{\mathrm{w}} h_{\text {crust }}\right]}
$$

to be $h_{\mathrm{emb}}+h_{\mathrm{s}, \mathrm{comp}}+h_{\text {sur }}$ (cf. top of Fig. 1), since the embankment will settle in accordance with the predetermined $s_{\text {target }}$ (i.e. $\left.h_{\mathrm{s}, \mathrm{comp}}\right)$.

\section{Degree of consolidation}

In the evaluation of $U$ (equations (1)-(3)), the well resistance is here disregarded for simplicity, such that (cf. Hansbo, 1979, 1981; Hong \& Shang, 1998) embankment; $h_{\mathrm{emb}}$ is the final height of the embankment above ground level (see Fig. 4); $h_{\text {crust }}$ is the thickness of the dry crust; $\gamma_{\mathrm{emb}}^{\prime}$ is the effective unit weight taking into account any submersion of embankment material under the groundwater table; and $\gamma_{\mathrm{w}}$ is the unit weight of water taking into account the uplift effect on the submerged dry crust. In equation (27b), $\sigma_{0}^{\prime}$ is evaluated for the middle of the clay stratum (cf. equation (7)) and complete submersion of the dry crust is assumed; reformulation to take only partial submersion into account is straightforward. Moreover, because of 
the more rapid consolidation at the PVDs, increased horizontal load distribution area with depth is assumed negligible.

Having established the probability distributions for $S_{t_{\max }}^{\text {sur }}$ and OCR $t_{\text {max }}^{\text {sur }}$ for a range of $h_{\text {sur }}$, the respective probabilities of meeting the design criteria $\left(S_{t_{\max }}^{\text {sur }} \geq s_{\text {target }}\right.$ and $\mathrm{OCR}_{t_{\max }}^{\text {sur }} \geq 1 \cdot 10$ in the middle of the clay stratum) can be calculated for this range of $h_{\text {sur. }}$ The designing engineer then selects a suitable $h_{\text {sur }}$ that with acceptable probability satisfies the design criteria; this decision-theoretical consideration is further elaborated upon in the 'Discussion' section.

\section{ILLUSTRATIVE DESIGN EXAMPLE \\ Case description}

To illustrate the proposed design procedure, a practical example is presented, using real case data for the soil characterisation and embankment geometry. A $1.2 \mathrm{~m}$ high road embankment is to be constructed on $15.5 \mathrm{~m}$ of very soft clay (after unloading of $0.3 \mathrm{~m}$ of the dry crust). The embankment is located in the south of the county of Stockholm, Sweden, and has a width of $23 \mathrm{~m}$. A critical cross-section is presented in Fig. 5, for which the design is made. PVDs are to be installed to increase the rate of consolidation; this example considers only the specific PVD design described in Table 2 to make it possible to focus on the surcharge design. The available preloading time $\left(t_{\max }\right)$ is 15 months. Soil samples have been collected at the critical section and the results of this investigation are presented in Table 3, Figs 6 and 7. The deformation properties were evaluated with the CRS oedometer test (see Appendix), in accordance with the Swedish standard (SIS, 1991). Any

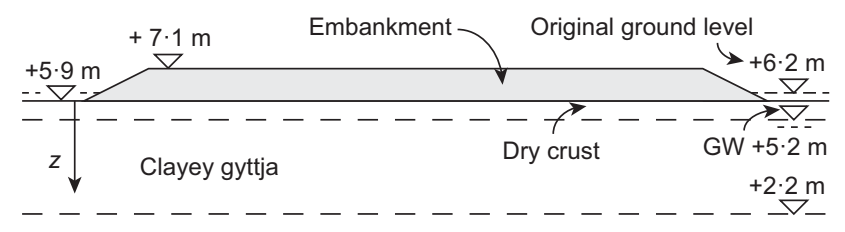

Varved clay

Somewhat silty, varved clay

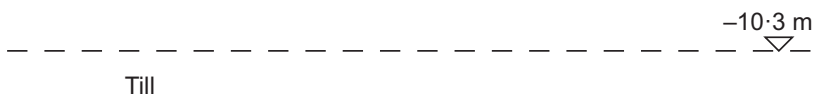

Fig. 5. Cross-section of analysed case

Table 2. PVD design in the illustrative design example

\begin{tabular}{l|l|l}
\hline Parameter & Symbol & Value \\
\hline Influence radius of drains* & $r_{\mathrm{e}}$ & $0.37 \mathrm{~m}$ \\
Drain radius & $r_{\mathrm{w}}$ & $0.033 \mathrm{~m}$ \\
Smear zone radius & $r_{\mathrm{s}}=2 r_{\mathrm{w}}$ & $0.066 \mathrm{~m}$ \\
Conductivity ratio of smeared zone & $k_{\mathrm{h}} / k_{\mathrm{h}}^{\prime}$ & 4 \\
Horizontal/vertical conductivity ratio & $k_{\mathrm{h}} / k_{\mathrm{v}}$ & $2 \cdot 5$ \\
Longest drain path $\dagger$ & $h_{\mathrm{dr}}$ & $7.75 \mathrm{~m}$ \\
\hline
\end{tabular}

*Equivalent to a triangular pattern with $0.7 \mathrm{~m}$ centre-to-centre drain spacing.

†Two-way drainage assumed. settlement of the dry crust and underlying till layer is disregarded.

\section{Probabilistic soil characterisation}

Since trend lines with depth are present for the investigated soil properties, the procedure for probabilistic soil characterisation outlined by equations (8)-(20) was applied on the random parameters (Figs 6 and 7). The clay stratum was divided into four layers (equation (25)).

For simplicity, measurement errors were not considered. Moreover, $c_{\mathrm{h}}$ was assumed to be $2 \cdot 5 c_{\mathrm{v}}$, which the Swedish Road Administration (SRA, 1989) suggests for Swedish clays and to which an unbiased log-normally distributed transformation error equivalent to $50 \%$ coefficient of variation (COV) was added (equation (20)). The value of $M^{\prime}$ was calculated by applying the established empirical relationship between $M^{\prime}$ and $w_{\mathrm{N}}$ (Larsson \& Sällfors, 1986) as a transformation model, $T$

$$
M^{\prime}=4 \cdot 5+\frac{6}{w_{N}}
$$

to which an unbiased normally distributed transformation error of $15 \%$ COV was assigned, based on the data that were used to derive the relationship. All geotechnical parameters were assumed mutually independent for simplicity, except for the parameters $\sigma_{\mathrm{c}}^{\prime}$ and $\sigma_{\mathrm{L}}^{\prime}$, which were assumed fully correlated to avoid the impossible case of having $\sigma_{\mathrm{L}}^{\prime}<\sigma_{\mathrm{c}}^{\prime}$ (cf. Fig. 3). Transformation errors and correlation were taken into account using numerical simulation of the probability distributions in Matlab.

\section{Evaluation of target settlement and degree of consolidation}

In this design example, the $p_{\mathrm{FT}}$ was set to $5 \%$, in line with Akbas \& Kulhawy (2009); see also Fenton et al. (2016). This implies a $5 \%$ probability of having post-completion settlements beyond $\Delta s_{\text {allow }}$. Reserving such allowable settlements for any remaining secondary compression settlement that still occurs despite the OCR requirement (equation (7)), the post-completion primary compression settlement was strictly limited in the design calculations - that is, $\Delta s_{\text {allow }}=0$.

Crude Monte Carlo simulation was used to generate 10000 samples for each parameter at each of the four layer centres from the evaluated random variables. To establish $s_{\text {target }}+\Delta s_{\text {allow }}$ as the $5 \%$ upper percentile of $S_{\infty}$, samples of $S_{\infty}$ (equation (25)) were iteratively generated for increasing $\Delta \sigma^{\prime}$ until the equality $\Delta \sigma^{\prime}=\gamma_{\mathrm{emb}}\left(h_{\mathrm{emb}}+h_{\text {crust }}\right)+\gamma_{\mathrm{emb}}^{\prime}\left(s_{\text {target }}-\right.$ $\left.h_{\text {crust }}\right)-\gamma_{\mathrm{w}} h_{\text {crust }}$ was satisfied, thereby compensating the embankment height for occurring settlements (see Fig. 4). This gave $s_{\text {target }}=1.34 \mathrm{~m}$ to be satisfied during the preloading phase (Fig. 8(a)). Samples of $U_{t_{\max }}$ were generated from a distribution (equations (1)-(3) and (26)) based on the deterministic parameters in Table 2 and the random $c_{\mathrm{v}}$ (Fig. 8(b)).

Evaluation of design criteria and other design considerations

To analyse the effect of different surcharge loads on the two design criteria, $S_{t_{\max }^{\text {sur }}}^{\text {sur }}$ and $\mathrm{OCR}_{t_{\max }}^{\text {sur }}$ (equation (27)) were evaluated for a range of surcharge loads: $0 \leq h_{\text {sur }} \leq 4 \mathrm{~m}$. The probabilities of them meeting their respective design criteria are shown in Fig. 9. For example, the OCR requirement is satisfied with $97 \%$ probability at $h_{\text {sur }}=1.25 \mathrm{~m}$; however, it is only $75 \%$ probable that $s_{\text {target }}$ will be attained before $t_{\max }$ for this load. A correlation analysis of the two design criteria provides additional valuable insights (Fig. 10): by analysing 
Table 3. Geotechnical parameters with probability distributions considered in the illustrative design example

\begin{tabular}{l|l|l}
\hline Parameter & Symbol & Comment \\
\hline Unit weight of clay & $\gamma_{\mathrm{cl}}$ & Seven samples (Fig. 6) \\
Natural water content & $w_{\mathrm{N}}$ & Seven samples (Fig. 6) \\
Preconsolidation pressure & $\sigma_{\mathrm{c}}^{\prime}$ & Nine samples (Fig. 7)* \\
Limit pressure towards increasing modulus & $\sigma_{\mathrm{L}}^{\prime}$ & Nine samples (Fig. 7)* \\
Modulus for $\sigma^{\prime} \leq \sigma_{\mathrm{c}}^{\prime}$ & $M_{0}$ & Nine samples (Fig. 7) \\
Modulus for $\sigma_{\mathrm{c}}^{\prime}<\sigma^{\prime} \leq \sigma_{\mathrm{L}}^{\prime}$ & $M_{\mathrm{L}}$ & Nine samples (Fig. 7) \\
Unit weight of the embankment & $\gamma_{\mathrm{emb}}$ & Assumed log-normally distributed with mean $20 \cdot 8 \mathrm{kN} / \mathrm{m}^{3}$ and COV of $5 \%$ \\
Vertical consolidation coefficient & $c_{\mathrm{v}}$ & Evaluated deterministically $\left(0 \cdot 2 \mathrm{~m} \mathrm{~m}^{2} / \mathrm{year}\right.$ ); $50 \% \mathrm{COV}$ assumed for all layers $\dagger$ \\
Horizontal consolidation coefficient & $c_{\mathrm{h}}$ & Calculated as $2 \cdot 5 c_{\mathrm{v}}$ with assumed $50 \% \mathrm{COV}$ for a log-normal $T_{\mathrm{i}}$ \\
\hline
\end{tabular}

$* \sigma_{\mathrm{c}}^{\prime}$ and $\sigma_{\mathrm{L}}^{\prime}$ were assumed perfectly correlated to avoid the impossible situation of having $\sigma_{\mathrm{c}}^{\prime}>\sigma_{\mathrm{L}}^{\prime}$.

$\dagger \mathrm{COV}$ in line with data presented by Lumb (1974).

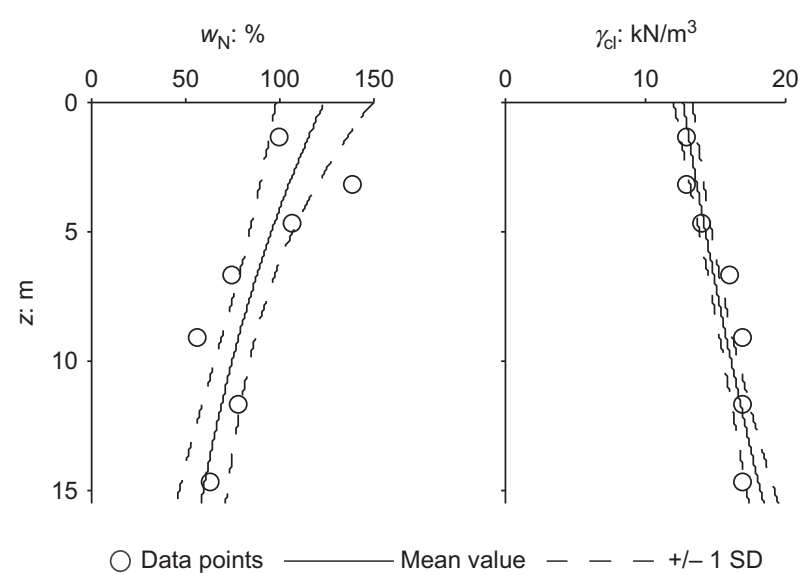

Fig. 6. Result of geotechnical investigation of water content, $w_{\mathrm{N}}$, and unit weight of the clay, $\gamma_{\mathrm{cl}}$ with assessment of variability of the exponential mean value trendlines presented as \pm 1 standard deviation (SD)

the underlying simulations of the probabilities in Fig. 9 for the considered $h_{\text {sur }}$ the initial surcharge load can also be selected with the unloading strategy in mind. For example, by applying $h_{\text {sur }}=1.25 \mathrm{~m}$, the settlement monitoring can be used not only to verify attainment of $s_{\text {target }}$, but also to ensure fulfilment of the OCR requirement, because Fig. 10(a) indicates that if the measured settlement will exceed $s_{\text {target }}$ within $t_{\max }$, the OCR $\mathrm{O}_{\text {target }}$ will also be satisfied. Conversely, for $h_{\text {sur }}=0.75 \mathrm{~m}$, exceedance of $s_{\text {target }}$ does not guarantee

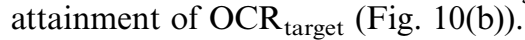

A suitable $h_{\text {sur }}$ for the preliminary design of the surcharge is selected considering the correlation analysis and the appetite for client's risk; the authors recommend selecting $h_{\text {sur }}$ such that the OCR target $_{\text {is attained before }} s_{\text {target }}$. The monitoring during preloading and the unloading strategy (discussed below) thereby both become straightforward, as one can rely on the observed vertical deformation for both targets.

If the surcharge has a considerable height, the stability may be unsatisfactory. This is normally managed by designing berms to the embankment slopes. It may also be favourable to install vertical drains under the berms, as consolidation improves the shear strength of the soil. For very high surcharges, a staged construction sequence may be required (see e.g. Müller et al., 2016). Installing vertical drains under the berms also considerably limits the horizontal deformation, which otherwise may impair the evaluation of the settlement monitoring during construction.

Following the framework of the observational method (Table 1), a monitoring plan to observe the settlements is prepared, along with alarm thresholds and a contingency action plan that describes how the surcharge shall be raised if an alarm threshold is violated.
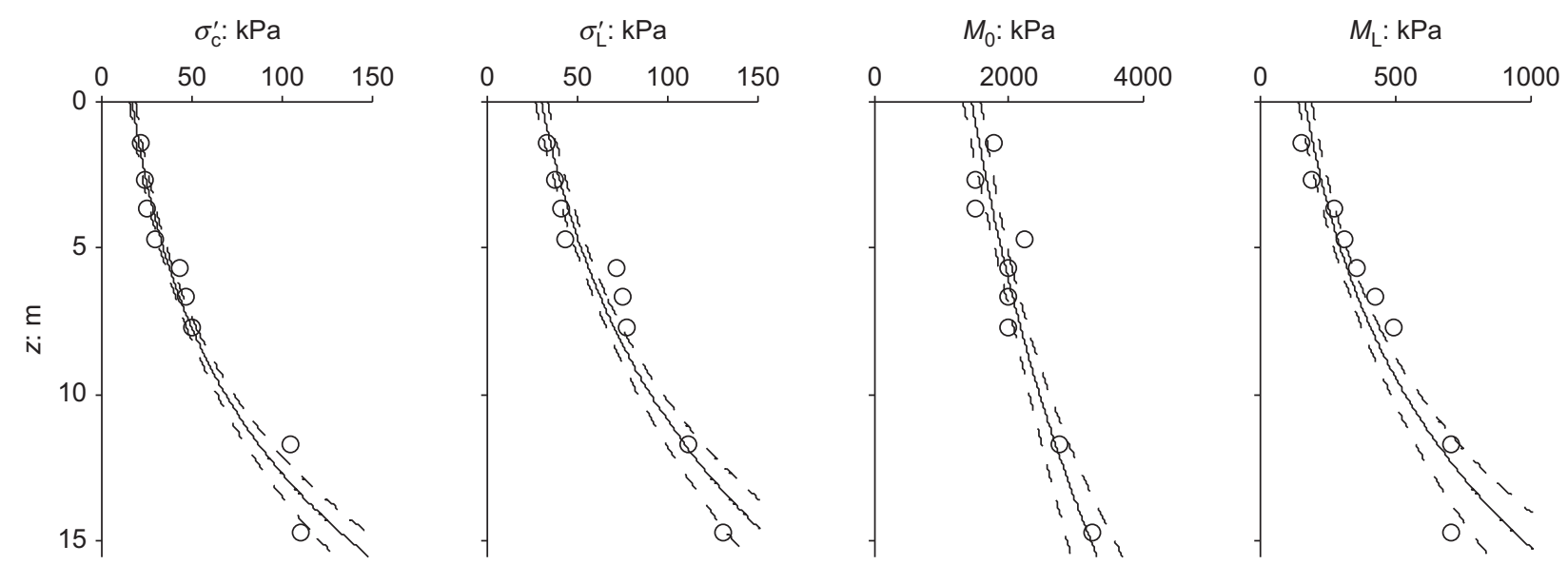

Data points

Mean value

$-\quad-+/-1$ Standard deviation

Fig. 7. Settlement parameters from CRS oedometer tests with assessment of variability of the exponential mean value trendlines presented as \pm 1 standard deviation 




(a)

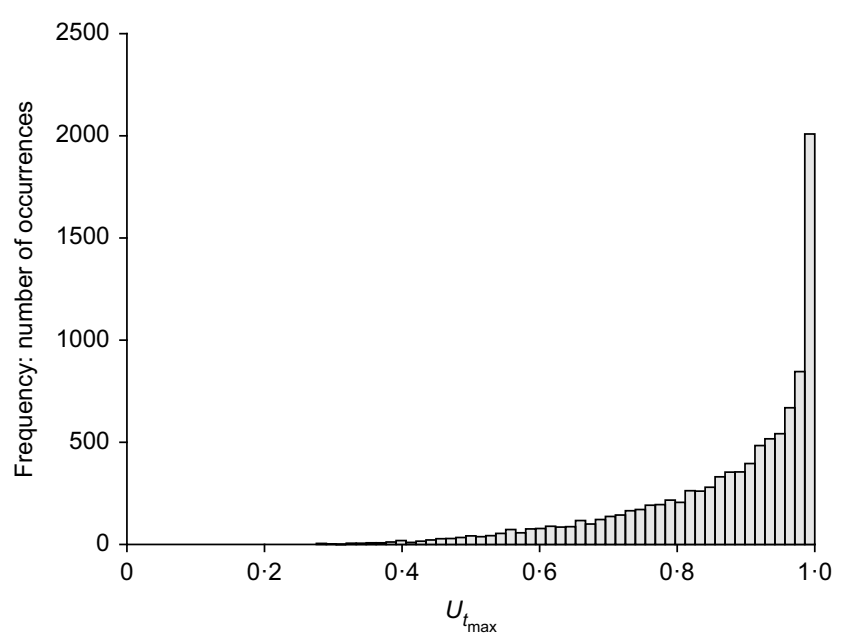

(b)

Fig. 8. Histograms of (a) total predicted settlement after infinite time, where $s_{\text {target }}$ was determined as the upper percentile corresponding to $p_{\mathrm{FT}}$; (b) distribution of $\boldsymbol{U}_{\boldsymbol{t}_{\max }}$

\section{Considerations during the preloading}

If the settlement and pore pressure measurements during the preloading indicate that the consolidation is taking longer than expected, the contingency action to raise the surcharge is applied to increase the rate of deformation so that the targets can be attained within $t_{\max }$. For a detailed discussion on monitoring of the consolidation process for embankments on clay, the authors refer the reader to Prästings et al. (2014).

If $h_{\text {sur }}$ has been selected as recommended above, it is crucial to unload the surcharge when $s_{\text {target }}$ is attained. If unloading is delayed, the continuing consolidation will decrease the volume of fill that is removed down to the final embankment crest level. This may leave the OCR requirement not fulfilled (equations (7) and (27b)), making significant secondary compression more likely to occur after completion of the embankment and the superstructure.

\section{DISCUSSION}

Decision-theoretical design considerations with respect to the observational method

As established in the earlier section entitled 'Overview of the design procedure', the engineer who designs the surcharge load and the vertical drains has to take significant uncertainties regarding the ground conditions into account. By

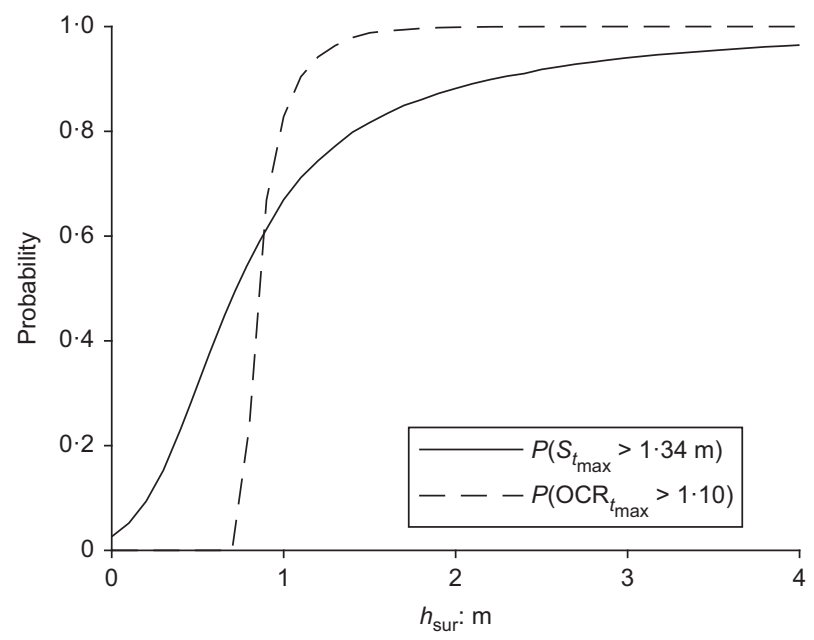

Fig. 9. Probability of satisfying the two design criteria for a range of $h_{\text {sur }}$ designing the surcharge with the observational method, these uncertainties can be managed cost-effectively. As shown in Fig. 9, the larger the surcharge load, the higher is the probability of satisfying the two design criteria. However, the engineer fortunately does not need to satisfy the design criteria with high probability, as the observational method offers the possibility to adjust the design to the actual conditions with a contingency action if the initial design should prove to be inadequate. Alternatively, the engineer may choose to apply a higher surcharge from the outset, at a higher initial cost but with the advantage of avoiding a cumbersome and potentially costly contingency action. The design challenge lies in comparing the cost and probability of having to raise the surcharge considerably after some time, with the certain cost associated with a higher initial surcharge.

What probability, $p_{\text {acc }}$, of successful initial surcharge height is acceptable then (see requirement 2(b) in Table 1)? In the authors' opinion, there is no specific value that can be used in all projects, but $p_{\text {acc }}$ needs to be established for each individual project by the appropriate risk owner - that is, the person responsible for achieving satisfactory quality in the project and who has the mandate to make decisions about risks. This follows from the general principles of geotechnical risk management (ISO, 2009; Spross et al., 2018).

The selection of $p_{\text {acc }}$ is not critical for the structural design; it is, in fact, only a matter of economic risk, as the prepared contingency action to raise the surcharge ensures that the design criteria, in principle, can be met during the available preloading time in all situations. The $p_{\text {acc }}$ will therefore depend on the risk owner's risk appetite. For reference, a risk-neutral decision maker (who finds the solution that minimises the statistically expected total project cost to be the most favourable) can find the optimal initial $h_{\text {sur }}$ by making a pre-posterior decision analysis using the reliability framework for the observational method outlined by Spross \& Johansson (2017). The complete decision analysis is not within the scope of this paper, but conceptually the outcome will largely depend on the cost and probability of having to raise the surcharge height as a contingency action, in relation to the certain cost of applying a higher surcharge from the outset. For example, if the contingency action is cheap because of large availability of material, it can be allowed with higher probability. Note, however, that a complete design analysis of the embankment should also consider the PVDs, as the probability of satisfying the design criteria can be increased by, for example, decreasing the drain spacing. 


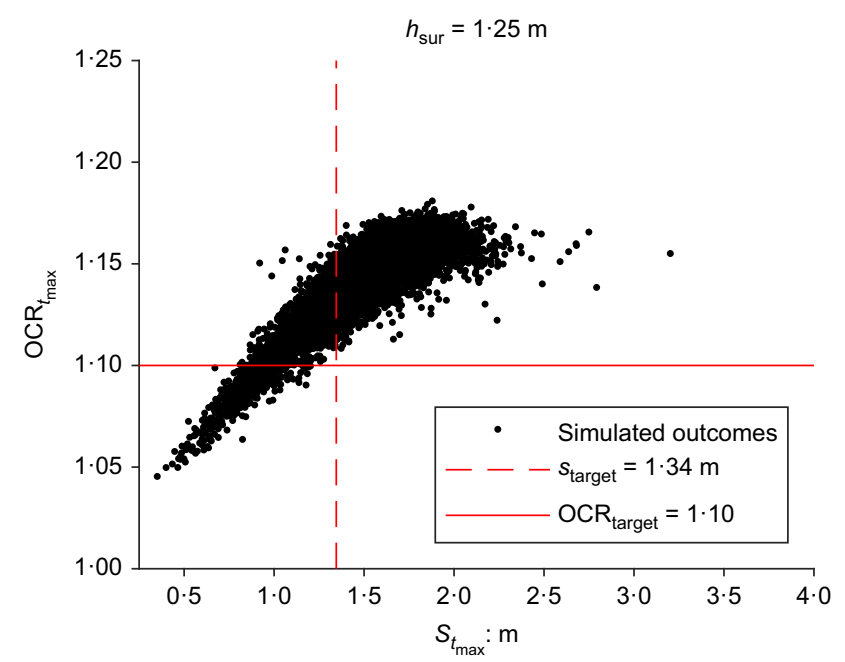

(a)

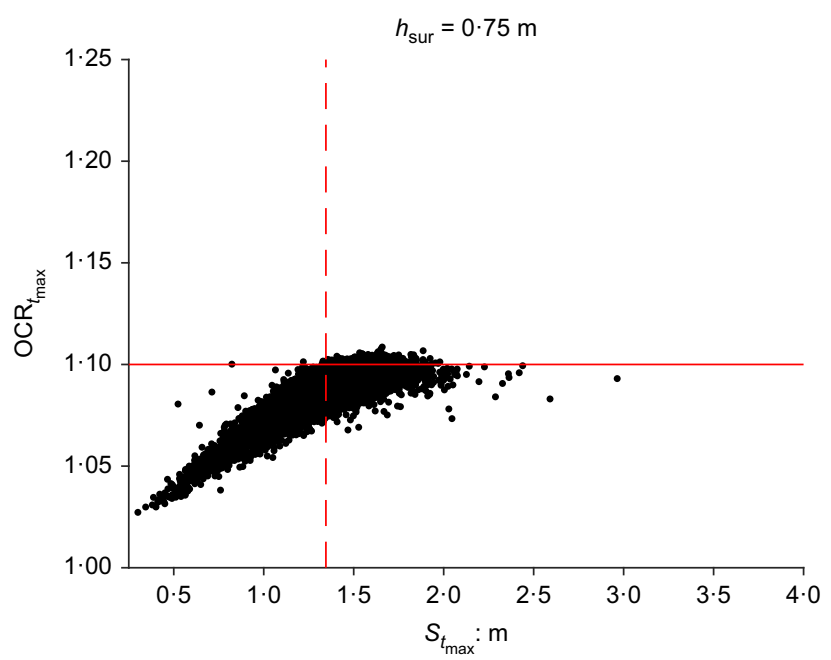

(b)

Fig. 10. Visualisation of the respective probabilities of satisfying the two design criteria for (a) $h_{\text {sur }}=1.25 \mathrm{~m}$ and (b) $h_{\text {sur }}=0.75 \mathrm{~m}$

Effect of spatial variability of soil properties on the design

The proposed design procedure does not consider spatial variability of the evaluated random parameters. However, the authors find this simplification reasonable when the design is made for a critical embankment section where the geotechnical investigation has also been carried out. The available information from the geotechnical investigation and the evaluated probability distributions therefore well represent the present knowledge of the geotechnical conditions on this particular section. A procedure that considers spatial variability and applies local averaging (e.g. Vanmarcke, 2010; Bari \& Shahin, 2014; Jiang et al., 2014; Mašín, 2015) would, however, be useful if an embankment section at some distance from the closest investigated soil volumes is to be analysed. This is therefore a natural future advance of the procedure. In practice, however, the authors believe that if $h_{\text {sur }}$ has been evaluated for a critical section of the embankment, using the same height for a longer stretch of the embankment should give sufficiently good results.

\section{CONCLUDING REMARKS}

This paper presents a novel probabilistic design procedure for embankments on soft clay that is compatible with the observational method. The procedure evaluates the suitable surcharge load to be used in combination with PVDs. While the procedure analyses the primary compression settlements of the clay, it also takes secondary compression into account by ensuring a sufficient degree of overconsolidation after unloading of the surcharge. The procedure highlights the considerable effect that the uncertainty regarding key geotechnical parameters - mainly the consolidation coefficients - has on the prediction of the rate of consolidation. Moreover, it is shown how the observational method can be efficiently applied to manage this uncertainty to avoid project delay. The involved analyses can also contribute considerably to managing some of the geotechnical risks in the construction of embankments.

\section{ACKNOWLEDGEMENT}

The authors would like to acknowledge the Swedish Transport Administration for funding this project and supplying data for the illustrative design example.

\section{APPENDIX \\ Constant-rate-of-strain oedometer tests}

In Swedish practice, incremental tests have mainly been replaced by CRS oedometer tests with drainage only at the top surface (SIS, 1991). The result is plotted as a stress-strain curve and a modulus-stress curve on linear scales (Fig. 3). The $\sigma_{\mathrm{c}}^{\prime}$ is evaluated by extending lines of the two straight parts of the stress-strain curve and inscribing an isosceles triangle between the lines and the stress-strain curve. The stress at the left angle gives the $\sigma_{\mathrm{c}}^{\prime}$. For better agreement with standard incremental tests, the stress-strain curve is then moved laterally a distance $c$, so that it passes through $\sigma_{\mathrm{c}}^{\prime}$ on the curve.

In the modulus-stress plot, the initial modulus $M_{0}$ is extended to $\sigma_{\mathrm{c}}^{\prime}$, at which point the modulus is assumed to drop instantly to $M_{\mathrm{L}}$. To evaluate $\sigma_{\mathrm{L}}^{\prime}$, the linearly increasing part of the modulus curve is moved $c \mathrm{kPa}$ to the left, giving $\sigma_{\mathrm{L}}^{\prime}$ at the intersection with $M_{\mathrm{L}}$. Lastly, $M^{\prime}$ is the slope of the linearly increasing part of the modulus curve. Because of swelling effects and sample disturbance, $M_{0}$ is regularly underpredicted in CRS tests. In practice, $M_{0}$ is therefore usually estimated from empirical relationships. Further details can be found in Larsson \& Sällfors (1986) and Larsson (1986).

\section{NOTATION}

$a$ intersection parameter evaluated from CRS

$\hat{a}$ regression parameter

$\hat{b}$ regression parameter

$C_{\mathrm{c}}$ compression index

$c_{\mathrm{h}} \quad$ coefficient of horizontal consolidation

$c_{\mathrm{v}}$ coefficient of vertical consolidation

$e_{0}$ initial void ratio

$F$ function describing the effect of drain spacing, soil disturbance and well resistance

$G$ limit state function

$h_{\text {clay }}$ total thickness of the saturated clay

$h_{\text {crust }}$ thickness of the dry crust

$h_{\mathrm{dr}}$ maximum vertical drain path

$h_{\text {emb }}$ final height of the embankment above ground level

$h_{j} \quad$ thickness of clay layer $j$

$h_{\mathrm{s}, \mathrm{comp}}$ required embankment height compensation for the occurring settlement

$h_{\text {sur }}$ surcharge height

I identity matrix

$k_{\mathrm{h}}$ horizontal hydraulic conductivity of the undisturbed soil

$k_{\mathrm{h}}^{\prime} \quad$ horizontal hydraulic conductivity of the disturbed soil

$l$ number of layers of clay stratum

$M^{\prime}$ soil modulus number evaluated from CRS

$M_{0} \quad$ soil modulus evaluated from CRS

$M_{\mathrm{L}} \quad$ soil modulus evaluated from CRS 


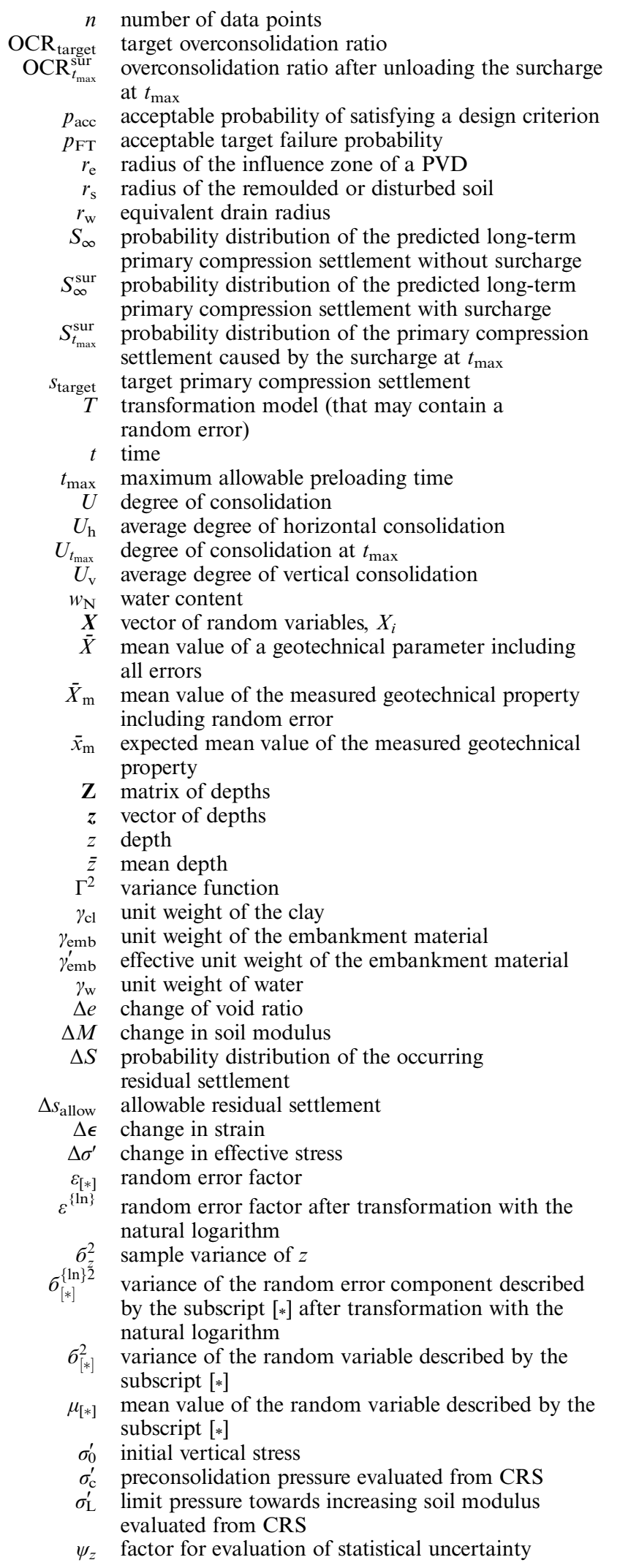

\section{SUBSCRIPTS}

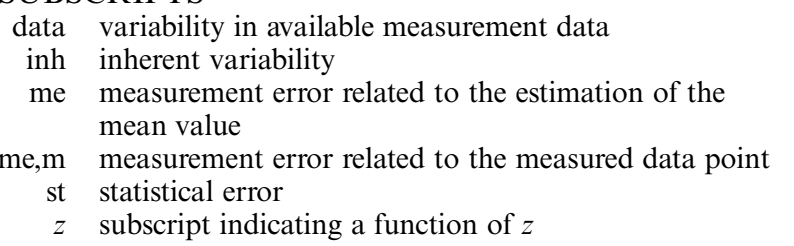

\section{REFERENCES}

Abdullah, W., Ramasamy, A., Talaat, A. \& Alotaibi, S. (2018). Verification of the preloading design of soft clay with prefabricated vertical drains by full-scale field instrumentation and numerical modelling. Int. J. Geotech. Engng 13, No. 1, 1-10, https://doi.org/10.1080/19386362.2018.1513674.

Abuel-Naga, H. M., Bergado, D. T. \& Gniel, J. (2015). Design chart for prefabricated vertical drains improved ground. Geotext. Geomembr. 43, No. 6, 537-546, https://doi.org/10.1016/ j.geotexmem.2015.04.021.

Akbas, S. O. \& Kulhawy, F. H. (2009). Reliability-based design approach for differential settlement of footings on cohesionless soils. J. Geotech. Geoenviron. Engng 135, No. 12, 1779-1788, https://doi.org/10.1061/(ASCE)GT.1943-5606.0000127.

Alonso, E. E., Gens, A. \& Lloret, A. (2000). Precompression design for secondary settlement reduction. Géotechnique 50, No. 6, 645-656, https://doi.org/10.1680/geot.2000.50.6.645.

Ang, A. H. S. \& Tang, W. H. (2007). Probability concepts in engineering: emphasis on applications to civil and environmental engineering. Hoboken, NJ, USA: John Wiley Publishers.

Atkinson, M. S. \& Eldred, P. J. L. (1981). Consolidation of soil using vertical drains. Géotechnique 31, No. 1, 33-43, https://doi.org/ 10.1680/geot.1981.31.1.33.

Baecher, G. B. \& Christian, J. T. (2003). Reliability and statistics in geotechnical engineering. Chichester, UK: John Wiley \& Sons.

Bari, M. W. \& Shahin, M. A. (2014). Probabilistic design of ground improvement by vertical drains for soil of spatially variable coefficient of consolidation. Geotext. Geomembr. 42, No. 1, 1-14, https://doi.org/10.1016/j.geotexmem.2013.11.001.

Bari, M. W., Shahin, M. A. \& Nikraz, H. R. (2013). Probabilistic analysis of soil consolidation via prefabricated vertical drains. Int. J. Geomech. 13, No. 6, 877-881, https://doi.org/10. 1061/(ASCE)GM.1943-5622.0000244.

Bari, M. W., Shahin, M. A. \& Soubra, A. H. (2016). Probabilistic analyses of soil consolidation by prefabricated vertical drains for single-drain and multi-drain systems. Int. J. Numer. Analyt. Methods Geomech. 40, No. 17, 2398-2420, https://doi.org/ 10.1002/nag. 2535 .

Barron, R. A. (1948). Consolidation of fine-grained soils by drain wells. Trans. Am. Soc. Civ. Engrs 113, No. 1, 718-754.

Bergado, D. T., Asakami, H., Alfaro, M. C. \& Balasubramaniam, A. S. (1991). Smear effects of vertical drains on soft Bangkok clay. J. Geotech. Engng 117, No. 10, 1509-1530, https://doi.org/10.1061/(ASCE)0733-9410(1991) 117:10(1509).

Bergman, N., Al-Naqshabandy, M. S. \& Larsson, S. (2013). Variability of strength and deformation properties in limecement columns evaluated from CPT and KPS measurements. Georisk 7, No. 1, 21-36, https://doi.org/10.1080/17499518.2013. 763571.

Bjureland, W., Spross, J., Johansson, F., Prästings, A. \& Larsson, S. (2017). Reliability aspects of rock tunnel design with the observational method. Int. J. Rock Mech. Min. Sci. 98, 102-110, https://doi.org/10.1016/j.ijrmms.2017.07.004.

Bong, T. \& Stuedlein, A. W. (2018). Efficient methodology for probabilistic analysis of consolidation considering spatial variability. Engng Geol. 237, 53-63, https://doi.org/10.1016/ j.enggeo.2018.02.009.

Bong, T., Son, Y., Noh, S. \& Park, J. (2014). Probabilistic analysis of consolidation that considers spatial variability using the stochastic response surface method. Soils Found. 54, No. 5, 917-926, https://doi.org/10.1016/j.sandf.2014.09.005.

Carrillo, N. (1942). Simple two and three dimensional case in the theory of consolidation of soils. Stud. Appl. Math. 21, No. 1-4, 1-5, https://doi.org/10.1002/sapm19422111.

CEN (European Committee for Standardisation) (2004). EN 1997-1:2004: Eurocode 7: geotechnical design - part 1: general rules. Brussels, Belgium: European Committee for Standardisation.

Ching, J. \& Phoon, K. K. (2012). Establishment of generic transformations for geotechnical design parameters. Struct. Saf. 35, 52-62, https://doi.org/10.1016/j.strusafe.2011.12.003.

Chung, S., Kweon, H. \& Jang, W. (2014). Observational method for field performance of prefabricated vertical drains. Geotext. Geomembr. 42, No. 4, 405-416, https://doi.org/10.1016/ j.geotexmem.2014.06.005. 
Feng, W. Q. \& Yin, J. H. (2018). A new simplified hypothesis B method for calculating the consolidation settlement of ground improved by vertical drains. Int. J. Numer. Analyt. Methods Geomech. 42, No. 2, 295-311, https://doi.org/10.1002/nag.2743.

Fenton, G. A. \& Griffiths, D. V. (2008). Risk assessment in geotechnical engineering. Hoboken, NJ, USA: John Wiley \& Sons.

Fenton, G. A., Naghibi, F. \& Griffiths, D. V. (2016). On a unified theory for reliability-based geotechnical design. Comput. Geotech. 78, 110-122, https://doi.org/10.1016/j.compgeo.2016. 04.013.

Fuentes, R., Pillai, A. \& Ferreira, P. (2018). Lessons learnt from a deep excavation for future application of the observational method. J. Rock Mech. Geotech. Engng 10, No. 3, 468-485, https://doi.org/10.1016/j.jrmge.2017.12.004.

Geng, X. \& Yu, H. S. (2017). A large-strain radial consolidation theory for soft clays improved by vertical drains. Géotechnique 67, No. 11, 1020-1028, https://doi.org/10.1680/jgeot.15.T.013.

Guo, W., Chu, J. \& Nie, W. (2018). An observational method for consolidation analysis of the PVD-improved subsoil. Geotext. Geomembr. 46, No. 5, 625-633. https://doi.org/10. 1016/j.geotexmem.2018.04.014.

Han, J. (2015). Principles and practice of ground improvement. Hoboken, NJ, USA: John Wiley \& Sons.

Hansbo, S. (1979). Consolidation of clay by band-shaped prefabricated drains. Ground Engng 12, No. 5, 16-25.

Hansbo, S. (1981). Consolidation of fine-grained soils by prefabricated drains. In Proceedings of the 10th international conference on soil mechanics and foundation engineering, Stockholm, Sweden, vol. 3, pp. 677-682. Rotterdam, the Netherlands: AA Balkema.

Hawlader, B. C., Muhunthan, B. \& Imai, G. (2003). Viscosity effects on one-dimensional consolidation of clay. Int. J. Geomech. 3, No. 1, 99-110, https://doi.org/10.1061/(ASCE)1532-3641(2003) 3:1(99).

Hird, C. C. \& Moseley, V. J. (2000). Model study of seepage in smear zones around vertical drains in layered soil. Géotechnique $\mathbf{5 0}$, No. 1, 89-97, https://doi.org/10.1680/geot.2000.50.1.89.

Hird, C. C. \& Sangtian, N. (2002). Model study of seepage in smear zones around vertical drains in layered soil: further results. Géotechnique 52, No. 5, 375-378, https://doi.org/10.1680/geot. 2002.52.5.375.

Hong, H. P. \& Shang, J. Q. (1998). Probabilistic analysis of consolidation with prefabricated vertical drains for soil improvement. Can. Geotech. J. 35, No. 4, 666-667, https://doi.org/ 10.1139/t98-031.

Huang, J., Griffiths, D. V. \& Fenton, G. A. (2010). Probabilistic analysis of coupled soil consolidation. J. Geotech. Geoenviron. Engng 136, No. 3, 417-430, https://doi.org/10.1061/(ASCE)GT. 1943-5606.0000238.

Indraratna, B. \& Redana, I. W. (1997). Plane-strain modelling of smear effects associated with vertical drains. J. Geotech. Geoenviron. Engng 123, No. 5, 474 478, https://doi.org/ 10.1061/(ASCE)1090-0241(1997)123:5(474).

Indraratna, B. \& Redana, I. W. (1998). Laboratory determination of smear zone due to vertical drain installation. J. Geotech. Geoenviron. Engng 124, No. 2, 180-184, https://doi.org/ 10.1061/(ASCE)1090-0241(1998)124:2(180).

Indraratna, B., Kan, M. E., Potts, D., Rujikiatkamjorn, C. \& Sloan, S. W. (2016). Analytical solution and numerical simulation of vacuum consolidation by vertical drains beneath circular embankments. Comput. Geotech. 80, 83-96, https:// doi.org/10.1016/j.compgeo.2016.06.008.

Indraratna, B., Zhong, R., Fox, P. J. \& Rujikiatkamjorn, C. (2017). Large-strain vacuum assisted consolidation with non-Darcian radial flow incorporating varying permeability and compressibility. J. Geotech. Geoenviron. Engng 143, No. 1, 04016088, https://doi.org/10.1061/(ASCE)GT.1943-5606. 0001599.

Indraratna, B., Baral, P., Rujikiatkamjorn, C. \& Perera, D. (2018a). Class $\mathrm{A}$ and $\mathrm{C}$ predictions for Ballina trial embankment with vertical drains using standard test data from industry and large diameter test specimens. Comput. Geotech. 93, 232-246, https://doi.org/10.1016/j.compgeo.2017.06.013.

Indraratna, B., Rujikiatkamjorn, C., Baral, P. \& Ameratunga, J. (2018b). Performance of marine clay stabilised with vacuum pressure: based on Queensland experience. J. Rock Mech. Geotech. Engng 11, No. 3, 598-611, https://doi.org/10.1016/ j.jrmge.2018.11.002.

ISO (International Organization for Standardization) (2009). ISO 31000: risk management - principles and guidelines. Geneva, Switzerland: International Organization for Standardization.

Jamiolkowski, M. \& Lancellotta, R. (1981). Consolidation by vertical drains: uncertainties involved in prediction of settlement rates. In Proceedings of the 10th international conference on soil mechanical and foundation engineering, Stockholm, Sweden, vol. 4, pp. 593-595. Rotterdam, the Netherlands: Balkema.

Jiang, S. H., Li, D. Q., Zhang, L. M. \& Zhou, C. B. (2014). Slope reliability analysis considering spatially variable shear strength parameters using a non-intrusive stochastic finite element method. Engng Geol. 168, 120-128, https://doi.org/10.1016/ j.enggeo.2013.11.006.

Kjellman, W. (1948). Accelerating consolidation of fine grain soils by means of cardboard wicks. In Proceedings of the 2nd international conference on soil mechanics and foundation engineering, Rotterdam, the Netherlands (eds N. Nanninga, G. A. Oosterholt, E. C. W. A. Geuze and A. W. Koppejan), vol. 2, pp. 302-305. Haarlem, the Netherlands: Gebr. Keesmaat.

Lacasse, S. \& Nadim, F. (1996). Uncertainties in characterising soil properties. In Uncertainty in the geologic environment: from theory to practice (eds C. D. Shackleford, P. P. Nelson and M. J. S. Roth), Geotechnical Special Publication 58, vol. 1, pp. 49-75. New York, NY, USA: American Society of Civil Engineers.

Larsson, R. (1986). Consolidation of soft soils, Report 29. Linköping, Sweden: Swedish Geotechnical Institute.

Larsson, R. \& Sällfors, G. (1986). Automatic continuous consolidation testing in Sweden. In Consolidation of soils: testing and evaluation (eds R. Yong and F. Townsend), pp. 299-328. West Conshohocken, PA, USA: ASTM International.

Lei, G. H., Zheng, Q., Ng, C. W. W., Chiu, A. C. F. \& Xu, B. (2015). An analytical solution for consolidation with vertical drains under multi-ramp loading. Géotechnique 65, No. 7, 531-547, https://doi.org/10.1680/geot.13.P.196.

Leroueil, S. (1996). Compressibility of clays: fundamental and practical aspects. J. Geotech. Engng 122, No. 7, 534-543, https://doi.org/10.1061/(ASCE)0733-9410(1996)122:7(534).

Lumb, P. (1974). Application of statistics in soil mechanics. In Soil mechanics: new horizons (ed. I. K. Lee), pp. 44-112 and 221-239. London, UK: Newnes-Butterworth.

Mašín, D. (2015). The influence of experimental and sampling uncertainties on the probability of unsatisfactory performance in geotechnical applications. Géotechnique 65, No. 11, 897-910, https://doi.org/10.1680/jgeot.14.P.161.

Müller, R. \& Larsson, S. (2013). Aspects on the modelling of smear zones around vertical drains. In Proceedings of the 18th international conference on soils mechanics and geotechnical engineering, Paris, France (eds P. Delage, J. Desrues, R. Frank, A. Puech and F. Schlosser), pp. 2965-2968. Paris, France: Comité Francais Mécanique des Sols et de Géotechnique.

Müller, R., Larsson, S. \& Spross, J. (2014). Extended multivariate approach for uncertainty reduction in the assessment of undrained shear strength in clays. Can. Geotech. J. 51, No. 3, 231-245, https://doi.org/10.1139/cgj-2012-0176.

Müller, R., Larsson, S. \& Spross, J. (2016). Multivariate stability assessment during staged construction. Can. Geotech. J. 53, No. 4, 603-618, https://doi.org/10.1139/cgj-2015-0037.

Nguyen, B. P. \& Kim, Y. T. (2019). Radial consolidation of PVD-installed normally consolidated soil with discharge capacity reduction using large-strain theory. Geotext. Geomembr. 47, No. 2, 243-254, https://doi.org/10.1016/ j.geotexmem.2019.01.008.

Ni, P., Xu, K., Mei, G. \& Zhao, Y. (2019). Effect of vacuum removal on consolidation settlement under a combined vacuum and surcharge preloading. Geotext. Geomembr. 47, No. 1, 12-22, https://doi.org/10.1016/j.geotexmem.2018.09.004.

Nicholson, D. P. (ed.) (1996). The observational method in geotechnical engineering. London, UK: Thomas Telford.

Peck, R. B. (1969). Advantages and limitations of the observational method in applied soil mechanics. Géotechnique 19, No. 2, 171-187, https://doi.org/10.1680/geot.1969.19.2.171. 
Phoon, K. K. \& Kulhawy, F. H. (1999). Characterization of geotechnical variability. Can. Geotech. J. 36, No. 4, 612-624, https://doi.org/10.1139/t99-038.

Porter, O. J. (1936). Studies of fill construction over mud flats including a description of experimental construction using vertical sand drains to hasten stabilization. In Proceedings of the international conference on soil mechanics and foundation engineering, Cambridge, MA, USA, Section L, pp. 229-235. Cambridge, MA, USA: Harvard University Press.

Prästings, A., Müller, R. \& Larsson, S. (2014). The observational method applied to a high embankment founded on sulphide clay. Engng Geol. 181, 112-123, https://doi.org/10.1016/ j.enggeo.2014.07.003.

Raiffa, H. \& Schlaifer, R. (1961). Applied statistical decision theory. Boston, MA, USA: Division of Research, Harvard Business School.

Rujikiatkamjorn, C., Ardana, M., Indraratna, B. \& Leroueil, S. (2013). Conceptual model describing smear zone caused by mandrel action. Géotechnique 63, No. 16, 1377-1388, https://doi.org/10.1680/geot.12.P.138.

Sharma, J. S. \& Xiao, D. (2000). Characterization of a smear zone around vertical drains by large-scale laboratory tests. Can. Geotech. J. 37, No. 6, 1265-1271, https://doi.org/10.1139/ t00-050.

SIS (Swedish Standards Institute) (1991). SS 027126: geotekniska provningsmetoder - kompressionsegenskaper - Ödometerförsök, CRS-försök - kohesionsjord (SS 027126: geotechnical tests compression properties - oedometer test, CRS tests - cohesive soil). Stockholm, Sweden: Swedish Standards Institute (in Swedish).

Spross, J. \& Gasch, T. (2019). Reliability-based alarm thresholds for structures analysed with the finite element method. Struct. Saf. 76, 174-183, https://doi.org/10.1016/j.strusafe.2018.09.004.

Spross, J. \& Johansson, F. (2017). When is the observational method in geotechnical engineering favourable? Struct. Saf. 66, 17-26, https://doi.org/10.1016/j.strusafe.2017.01.006.

Spross, J. \& Larsson, S. (2014). On the observational method for groundwater control in the northern link tunnel project, Stockholm, Sweden. Bull. Engng Geol. Environ. 73, No. 2, 401-408, https://doi.org/10.1007/s10064-013-0501-8.

Spross, J., Johansson, F., Uotinen, L. K. T. \& Rafi, J. Y. (2016). Using observational method to manage safety aspects of remedial grouting of concrete dam foundations. Geotech. Geol. Engng 34, No. 5, 1613-1630, https://doi.org/10.1007/ s10706-016-0069-8.

Spross, J., Olsson, L. \& Stille, H. (2018). The Swedish Geotechnical Society's methodology for risk management: a tool for engineers in their everyday work. Georisk 12, No. 3, 183-189, https:// doi.org/10.1080/17499518.2017.1416643.
SRA (Swedish Road Administration) (1989). Vertikaldränering: allmän teknisk beskrivning - metoder (Vertical drains: general technical guidelines - methods). Borlänge, Sweden: Swedish Road Administration (in Swedish).

STA (Swedish Transport Administration) (2013a). TK Geo 13: Trafikverkets tekniska rav för geokonstruktioner (Swedish Transport Administration's technical requirements on geotechnical engineering structures). Borlänge, Sweden: Trafikverket (Swedish Transport Administration) (in Swedish).

STA (2013b). TR Geo 13: Trafikverkets tekniska råd för geokonstruktioner (Swedish Transport Administration's technical guidelines for geotechnical engineering structures). Borlänge, Sweden: Trafikverket (Swedish Transport Administration) (in Swedish).

Stark, T. D., Ricciardi, P. J. \& Sisk, R. D. (2017). Case study: vertical drain and stability analyses for a compacted embankment on soft soils. J. Geotech. Geoenviron. Engng 144, No. 2, 05017007 , https://doi.org/10.1061/(ASCE)GT.1943-5606.0001786.

Tang, W. H. (1980). Bayesian frequency analysis. J. Hydraul. Div. 106, No. 7, 1203-1218.

Vanmarcke, E. H. (2010). Random fields: analysis and synthesis. Hackensack, NJ, USA: World Scientific Publishing.

Vrouwenvelder, A. C. W. M. (2002). Developments towards full probabilistic design codes. Struct. Saf. 24, No. 2, 417-432, https://doi.org/10.1016/S0167-4730(02)00035-8.

Walker, R. \& Indraratna, B. (2007). Vertical drain consolidation with overlapping smear zones. Géotechnique 57, No. 5, 463-467, https://doi.org/10.1680/geot.2007.57.5.463.

Wang, J., Fang, Z., Cai, Y., Chai, J., Wang, P. \& Geng, X. (2018). Preloading using fill surcharge and prefabricated vertical drains for an airport. Geotext. Geomembr. 46, No. 5, 575-585, https://doi.org/10.1016/j.geotexmem.2018.04.013.

Wang, J., Gao, Z., Fu, H., Ding, G., Cai, Y., Geng, X. \& Shi, C. (2019). Effect of surcharge loading rate and mobilized load ratio on the performance of vacuum-surcharge preloading with PVDs. Geotext. Geomembr. 47, No. 2, 121-127, https:// doi.org/10.1016/j.geotexmem.2018.12.001.

Wu, T. H. (2011). 2008 Peck lecture: the observational method: case history and models. J. Geotech. Geoenviron. Engng 137, No. 10, 862-873, https://doi.org/10.1061/(ASCE)GT.1943-5606. 0000509.

Zhou, Y. \& Chai, J. C. (2017). Equivalent 'smear' effect due to non-uniform consolidation surrounding a PVD. Géotechnique 67, No. 5, 410-419, https://doi.org/10.1680/jgeot. 16.P.087.

Zhou, W., Hong, H. P. \& Shang, J. Q. (1999). Probabilistic design method of prefabricated vertical drains for soil improvement. J. Geotech. Geoenviron. Engng 125, No. 8, 659-664, https://doi.org/10.1061/(ASCE)1090-0241(1999)125:8 (659). 